Article

\title{
Curcumin Attenuates Lead-Induced Cerebellar Toxicity in Rats via Chelating Activity and Inhibition of Oxidative Stress
}

\author{
Kabeer Abubakar ${ }^{1,2, *(\mathbb{D}}$, Maryam Muhammad Mailafiya ${ }^{1,2}\left(\mathbb{D}\right.$, Abubakar Danmaigoro ${ }^{3}(\mathbb{D}$, \\ Samaila Musa Chiroma ${ }^{1,4}\left[\right.$, Ezamin Bin Abdul Rahim ${ }^{5, * \mathbb{C}}$ and Md Zuki Abu Bakar @ Zakaria ${ }^{6}$ \\ 1 Department of Human Anatomy, Faculty of Medicine and Health Sciences, University Putra Malaysia, \\ 43400 Serdang, Selangor Darul Ehsan, Malaysia \\ 2 Department of Human Anatomy, College of Medical Sciences, Federal University Lafia, P.M.B 146 Akunza, \\ Lafia, Nasarawa State, Nigeria \\ 3 Department of Veterinary Anatomy, Faculty of Veterinary Medicine, Usman Danfodiyo University, \\ P.M.B 2346 Sokoto, Nigeria \\ 4 Department of Human Anatomy, Faculty of Basic Medical Sciences, University of Maiduguri, \\ Borno State, Nigeria \\ 5 Department of Radiology, Faculty of Medicine and Health Sciences, University Putra Malaysia, \\ 43400 Serdang, Selangor Darul Ehsan, Malaysia \\ 6 Department of Preclinical Sciences Faculty of Veterinary Medicine, University Putra Malaysia, \\ 43400 Serdang, Selangor Darul Ehsan, Malaysia \\ * Correspondence: kabeernakhadee@yahoo.com (K.A.); drezahar@gmail.com (E.B.A.R.); \\ Tel.: +60182018569 (K.A.); +60196846933 (E.B.A.R.)
}

Received: 21 June 2019; Accepted: 25 July 2019; Published: 6 September 2019

\begin{abstract}
Lead $(\mathrm{Pb})$ is a toxic, environmental heavy metal that induces serious clinical defects in all organs, with the nervous system being its primary target. Curcumin is the main active constituent of turmeric rhizome (Curcuma longa) with strong antioxidant and anti-inflammatory properties. This study is aimed at evaluating the therapeutic potentials of curcumin on $\mathrm{Pb}$-induced neurotoxicity. Thirty-six male Sprague Dawley rats were randomly assigned into five groups with 12 rats in the control (normal saline) and 6 rats in each of groups, i.e., the lead-treated group (LTG) (50 mg/kg lead acetate for four weeks), recovery group (RC) $(50 \mathrm{mg} / \mathrm{kg}$ lead acetate for four weeks), treatment group 1 (Cur100) (50 mg/kg lead acetate for four weeks, followed by $100 \mathrm{mg} / \mathrm{kg}$ curcumin for four weeks) and treatment group 2 (Cur200) (50 mg/kg lead acetate for four weeks, followed by $200 \mathrm{mg} / \mathrm{kg}$ curcumin for four weeks). All experimental groups received oral treatment via orogastric tube on alternate days. Motor function was assessed using a horizontal bar method. The cerebellar concentration of $\mathrm{Pb}$ was evaluated using ICP-MS technique. $\mathrm{Pb}$-administered rats showed a significant decrease in motor scores and Superoxide Dismutase (SOD) activity with increased Malondialdehyde (MDA) levels. In addition, a marked increase in cerebellar $\mathrm{Pb}$ concentration and alterations in the histological architecture of the cerebellar cortex layers were recorded. However, treatment with curcumin improved the motor score, reduced $\mathrm{Pb}$ concentration in the cerebellum, and ameliorated the markers of oxidative stress, as well as restored the histological architecture of the cerebellum. The results of this study suggest that curcumin attenuates $\mathrm{Pb}$-induced neurotoxicity via inhibition of oxidative stress and chelating activity.
\end{abstract}

Keywords: curcumin; lead toxicity; ICP-MS; horizontal bar; motor coordination; oxidative stress; cerebellum 


\section{Introduction}

Lead $(\mathrm{Pb})$ is a ubiquitous environmental neurotoxin that induces several physiological, behavioral, and biochemical abnormalities in humans and animals [1]. Pb toxicity remains a common problem in both developing and industrialized countries due to unavoidable environmental and occupational exposure, resulting in about 600,000 new cases of intellectual disabilities in children and 143,000 deaths per year [1,2]. Although data from the Adults Blood Lead Epidemiology and Surveillance (ABLES) program indicate a significant decrease in the incidence of blood lead levels (BLLs) among adult industrial workers, occupational exposure to $\mathrm{Pb}$ remains a public health concern, accounting for about 94\% of $\mathrm{Pb}$ exposure [3]. Occupational exposure to $\mathrm{Pb}$ is linked to several health consequences, such as cognitive impairment, reproductive disorders, hypertension, motor dysfunction, cancer, hepatotoxicity, nephrotoxicity, and mortality $[4,5]$.

The mechanism of $\mathrm{Pb}$ toxicity is due to its ability to induce oxidative stress via disruption of the oxidant/antioxidant balance mechanism in cells [6]. Pb, a ubiquitous toxin, is known to induce oxidative stress by increasing the generation of reactive oxygen species (ROS), such as hydroxyl radicals, lipid peroxides, superoxide radicals, and hydrogen peroxide [6]. Pb toxicity has long been linked with impaired motor function, particularly deficits in visuomotor coordination among adult industrial workers and children exposed to $\mathrm{Pb}$ [7]. However, studies on the effect of $\mathrm{Pb}$ exposure on visuomotor integration among Yugoslavian and urban African American children showed that blood lead levels (BLLs) contributed significantly to poorer fine motor skills, as well as gross motor speed [7,8]. When treated with $\mathrm{Pb}$, animal models display increased oxidative stress, cognitive impairments, degeneration of neurons, deficits in motor coordination, and mortality [9-11].

There has been great advancement in the field of phytotherapy, with marked increased in the use of medicinal plants such as curcumin as phytotherapeutics due to its pharmacological safety and antioxidant properties against heavy metal poisoning [12-15]. Chelation therapy is a recommended strategy in the treatment and management of chronic $\mathrm{Pb}$ poisoning, however, the major limiting factor regarding chelation therapy is some chelating agents could have a nonspecific action, resulting in the removal of essential metals from the body [16,17]. Further, application of chelation therapy in the treatment of chronic $\mathrm{Pb}$ poisoning is associated with several side effects, such as brain damage, anemia, liver and kidney diseases, anaphylactic shock, and others [16,18]. Curcumin is the main natural polyphenol in the rhizome of turmeric (Curcuma longa); it belongs to the family of ginger (Zingiberaceae), which is widely used as a traditional medicine and food in Asia [19]. It is a lipophilic, phenolic, and water-insoluble compound which has antioxidant, anti-inflammatory, and anti-cancer properties [20]. Curcumin exhibits its strong antioxidant properties by increasing the production of antioxidant enzymes, thus resulting in the scavenging of excess ROS and inhibition of lipid peroxidation [21]. Curcumin is lipophilic, thus it has the potential to cross the blood-brain barrier (BBB) and bind to plaques in the brain, thereby inhibiting amyloid- $\beta$ peptide aggregation in Alzheimer's disease [22]. Post-treatment with curcumin in subarachnoid hemorrhage (SAH)-induced mice preserved the integrity of the BBB and improved brain function via down-regulation of matrix metallopeptidase 9 (MMP-9) and inhibition of microglia cells, as well as reducing water content in the brain [23].

The mechanism of neuroprotection exerted by curcumin on neurodegenerative disorders is mainly due to its ability to bind redox-active transition metal ions, such as $\mathrm{Mn}^{2+}, \mathrm{Fe}^{2+}, \mathrm{Cu}^{2+}$, and $\mathrm{Zn}^{2+}$, to form active and tight complexes [24]. Additionally, curcumin has a wide range of pharmacological activities and a good safety margin and it is identified as a natural drug against neurodegenerative disorders [24]. However, there is a paucity of knowledge on the therapeutic potentials of curcumin in $\mathrm{Pb}$-induced cerebellar toxicity. Therefore, the present study aimed at investigating the neurotherapeutic potential of curcumin on $\mathrm{Pb}$-induced cerebellar toxicity in rats. 


\section{Materials and Methods}

\subsection{Chemicals}

Lead acetate $\left.\left(\mathrm{CH}_{3} \mathrm{CO}_{2}\right)_{2} \mathrm{~Pb} \cdot 3 \mathrm{H}_{2} 0,99 \%\right)$ and animal feed were purchased from Sigma-Aldrich (St. Louis, MO, USA), while Malondialdehyde (MDA) ELISA and Superoxide Dismutase (SOD) assay kits were purchased from Elabscience (Houston, TX, USA). Curcumin, sodium acetate, aniline solution, and colophonium were purchased from Apical Scientific Sendirian. Berhad, Malaysia. All other chemicals used were of high analytical grade.

\subsection{Animals}

Thirty-six male Sprague Dawley rats aged 8 weeks, weighing 200-250 g, were obtained from the Animal Breeding Unit, Faculty of Veterinary Medicine, Universiti Putra Malaysia (UPM). The rats were kept in plastic cages and maintained at room temperature of $25 \pm 2{ }^{\circ} \mathrm{C}$ with a $12 \mathrm{~h}$ light-dark cycle. All rats had free access to food and water during the study period. The rats were allowed to acclimatize for one week prior to the experiment in the animal house, Faculty of Medicine and Health Science, UPM. The animal management and handling procedures were performed based on the recommended institutional animal care and use committee (IACUC) guidelines with the reference number UPM/IACUC/AUP-R038/2018, approved on 19 September 2018.

\subsection{Experimental Design}

The rats were randomly divided into five groups (group A, B, C, D, and E) with six rats each in group B, C, D, and E, while group A consisted of twelve rats. Group A (normal control group), received normal saline orally for the whole of the experiment (8 weeks). Group B was designated as the lead-treated group (LTG) and received $50 \mathrm{mg} / \mathrm{kg}$ of Pb acetate orally for 4 weeks (induction of lead toxicity). Group C was designated as the recovery group (RC) and receives $50 \mathrm{mg} / \mathrm{kg}$ of $\mathrm{Pb}$ acetate orally for 4 weeks, followed by no treatment for 4 weeks. Group D, also known as treatment group 1 (Cur100) received $50 \mathrm{mg} / \mathrm{kg}$ of $\mathrm{Pb}$ acetate for 4 weeks orally, followed by $100 \mathrm{mg} / \mathrm{kg}$ of curcumin for another 4 weeks. Group E was designated as treatment group 2 (Cur200) and received $50 \mathrm{mg} / \mathrm{kg}$ of Pb acetate for 4 weeks orally, followed by $200 \mathrm{mg} / \mathrm{kg}$ of curcumin for another 4 weeks. At the end of the 4 weeks of oral administration of $\mathrm{Pb}$ acetate, six rats each from group $\mathrm{A}$ and group $\mathrm{B}$ were euthanized to confirm $\mathrm{Pb}$ toxicity via histopathological examination. At the end of the experiment (week 8 ) all rats were sacrificed and tissues were harvested for biochemical and histopathological examinations. Motor activity and weight of the rats was evaluated weekly (Figure 1). The dose of $\mathrm{Pb}$ acetate $[25,26]$ and curcumin [27] was selected based on previous studies. The choice of oral administration of $50 \mathrm{mg} / \mathrm{kg} \mathrm{Pb}$ acetate was chosen to mimic environmental exposure in humans; it is commonly used as $\mathrm{Pb}$ poisoning in rats models. $\mathrm{Pb}$ is present in different environmental media, such as air, water, sediments, and soil, although the major source of environmental exposure to $\mathrm{Pb}$ is attributed to drinking water [28]. However, the health consequences of $\mathrm{Pb}$ exposure depend on the cumulative dose and vulnerability of the individual rather than the environmental media that harbors the $\mathrm{Pb}$ [29]. Worthy to note is that populations that are highly susceptible to $\mathrm{Pb}$ exposure are affected even at low levels of exposure, which results in several pathologies, such as neurodegenerative disease, reproductive and hepato-renal disorders, decreased intelligence quotient (IQ) levels, and cardiovascular disease [28,30]. The doses of curcumin at 100 and $200 \mathrm{mg} / \mathrm{kg}$ in previous studies showed no sign of toxicity or morbidity, as they were effective in attenuation of nerve degeneration, motor dysfunction, cerebral ischemia, and impaired tight-junction protein integrity in rats [27,31,32]. Hence, curcumin 100 and $200 \mathrm{mg} / \mathrm{kg}$ were adopted in this study. 


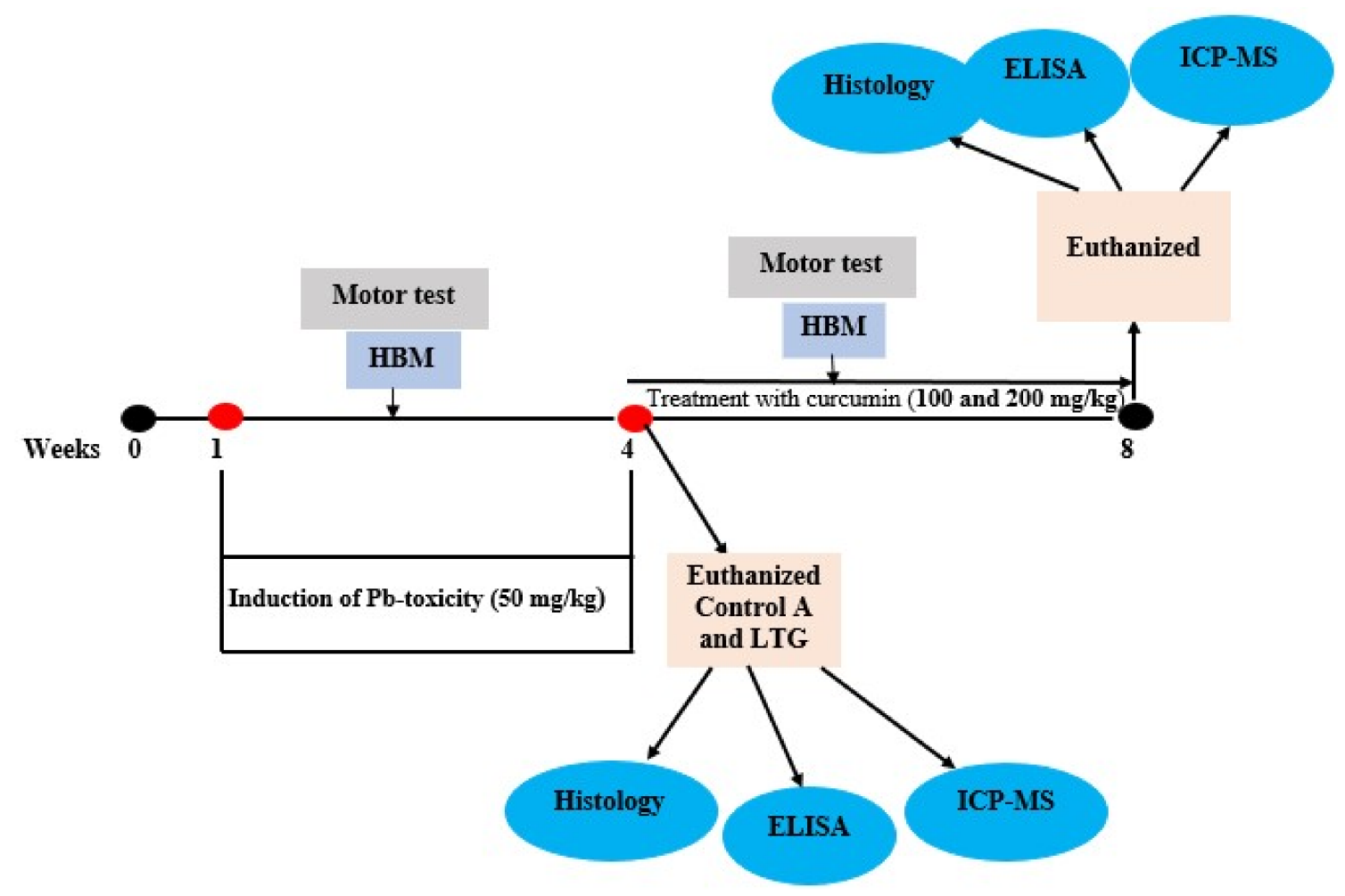

Figure 1. Schematic representation of the experimental design. HBM: Horizontal bar method; LTG: Lead-treated group; ICP-MS: Inductive coupled plasma spectrometry.

\subsection{Motor Activity}

Motor activity of the rats was evaluated using the horizontal bar method.

\section{Horizontal Bar Method}

The horizontal bar method is a test that measures forelimb strength and coordination in rodents. It involves the use of metal bars that were $2 \mathrm{~mm}$ in diameter and $38 \mathrm{~cm}$ long, suspended horizontally $49 \mathrm{~cm}$ above with support at two ends by a laboratory clamp and a padded surface to ensure soft landing of the experimental animals. The rats were placed on the center of the metal bar by handling them through their tail to ensure that only the forepaws grasped the metal bar. The falling time of the rats was recorded by a stopwatch and subsequently translated into scores as described by Deacon [33]. Scoring procedures used in the horizontal bar method are listed in Table 1.

Table 1. Scoring procedures in the horizontal bar method.

\begin{tabular}{clc}
\hline Serial No. & \multicolumn{1}{c}{ Duration of Rat on Horizontal Bar } & Score \\
\hline 1. & Falling time between 1 and $5 \mathrm{~s}$ & 1 \\
2. & Falling time between 6 and $10 \mathrm{~s}$ & 2 \\
3. & Falling time between 11 and $20 \mathrm{~s}$ & 3 \\
4. & Falling time between 21 and $30 \mathrm{~s}$ & 4 \\
5. & Falling time after $30 \mathrm{~s}$ & 5 \\
6. & The maximum score (5) was allotted if the rat placed one forepaw on the bar & 5 \\
& support without falling. & \\
\hline
\end{tabular}

Note 1: If the experimental animal failed to grasp the bar properly and its was obviously due to error of the experimenter, the test was repeated after a brief rest by the rat to obtain a falling time greater than $5 \mathrm{~s}$. Note 2: If the rat in three different attempts fell before $5 \mathrm{~s}$ and it appeared that it was not due to error of the experimenter in placing the rat on the bar, it was recorded and the best score was taken for the data. 


\subsection{Oxidative Stress Biomarker Analysis}

\subsubsection{Determination of Protein Concentration}

The total protein concentrations of the cerebellar homogenates were measured using the bicinchoninic acid assay (BCA assay). Bovine serum albumin (BSA) $(2 \mathrm{mg} / \mathrm{mL})$ was used as the standard with a working range of $125-2000 \mu \mathrm{g} / \mathrm{mL}$

\subsubsection{Antioxidant Enzyme Activity Analysis}

Superoxide dismutase (SOD) enzyme activity was determined in the rats' cerebellum homogenates using an SOD assay kit (Elabscience, E-BC-K020). The reaction mixture consisted of $20 \mu \mathrm{L}$ of tissue homogenates, $20 \mu \mathrm{L}$ of enzyme working solution, and $200 \mu \mathrm{L}$ of substrate application solution fully mixed and incubated at $37^{\circ} \mathrm{C}$ for $20 \mathrm{~min}$. The absorbance was measured at a wavelength of $450 \mathrm{~nm}$ using a micro-plate reader and the results were expressed as $\mathrm{U} / \mathrm{mg}$ protein.

\subsubsection{Malondialdehyde (MDA) Analysis}

The malondialdehyde level was determined from the rats' cerebellums using an MDA ELISA kit (E-EL-006, Elabscience, Houston, TX, USA), using the principle of competitive ELISA. The test was conducted according to manufacturer's manual (Elabscience, USA). Tissue pieces were washed, weighed, and homogenized in Phosphate-Buffered Saline (PBS) at a ratio of 1:9, with a glass homogenizer on ice. The homogenates were then centrifuged for $5 \mathrm{~min}$ at $5000 \times g$ to get the supernatant. The obtained supernatants were used to analyze the MDA using a micro-plate reader at a wavelength of $450 \mathrm{~nm}$. The results for MDA were expressed as $\mathrm{ng} / \mathrm{mL}$.

\subsection{Inductive Coupled Plasma Mass Spectrometry (ICP-MS)}

\subsubsection{Sample Preparation}

Harvested cerebellums from the rats were digested with $65 \%$ nitric acid using a microwave reaction system (Anton Paar, Multiwave PRO, Ashland, VA, USA),. About $0.5 \mathrm{~g}$ of the samples were placed in a Teflon vessel and $4 \mathrm{~mL}$ of nitric acid was added. The samples were then transferred into the microwave oven for $60 \mathrm{~min}$ to obtain a contamination-free, clear, digested solution. The solution was diluted with atomic water to $25 \mathrm{~mL}$ in agreement with digestion protocol as proposed by Rattanachongkiat et al. [34] and Simsek et al. [35].

\subsubsection{Sample analysis with ICP-MS}

$\mathrm{Pb}$ was determined with an Agilent $7700 \times$ inductively-coupled plasma mass spectrometer (Agilent Technologies, Barcelona, Spain) equipped with a Micro Mist nebulizer (Glass Expansion, Melbourne, Australia). Table 2 shows the parameters and operation conditions of Agilent $7700 \times$ ICP-MS. The results were quantified using external calibration standards. Each sample was digested and analyzed in duplicate. Quality control (QC) was performed by analyzing from 20 part per billion (ppb) of calibration standard for every three samples.

Table 2. Work specification resume for ICP-MS Agilent 7700× and measurement parameters.

\begin{tabular}{ccc}
\hline Parameters & Values & Units \\
\hline Radio Frequency Power & 1550 & $\mathrm{~W}$ \\
Radio Frequency Matching & 1.6 & $\mathrm{~V}$ \\
Sample depth & 9.5 & $\mathrm{~mm}$ \\
Torch & -0.1 & $\mathrm{~mm}$ \\
Torch-V & 0 & $\mathrm{~mm}$ \\
\hline
\end{tabular}


Table 2. Cont.

\begin{tabular}{ccc}
\hline Parameters & Values & Units \\
\hline Argon Gas Flow Rate & 15 & $\mathrm{~L} / \mathrm{min}$ \\
Carrier Gas Flow & 1.01 & $\mathrm{~L} / \mathrm{min}$ \\
Make up Gas Flow & 0.15 & $\mathrm{~L} / \mathrm{min}$ \\
Auxiliary Gas Flow Rate & 0.58 & $\mathrm{~L} / \mathrm{min}$ \\
Sample Uptake Rate & 0.3 & $\mathrm{revolutions} \mathrm{per} \mathrm{seconds} \mathrm{(rps)}$ \\
Sample Uptake Rate & 100 & $\mathrm{~mm}$ \\
Sampling Depth & $6-7.6$ & ${ }^{\circ} \mathrm{C}$ \\
Spray chamber temperature & 2 & revolution per seconds (rps) \\
Nebulizer Pump & 0.1 & $\mathrm{~s}$ \\
Integration Time & 3 & part per billion (ppb) \\
\hline Internal Standard $\left({ }^{103} \mathrm{Rh},{ }^{208} \mathrm{Bi}\right)$ & 200 &
\end{tabular}

\subsection{Histopathological Examination and Scoring}

The rats' cerebellums were fixed in 10\% buffered formalin for 5 days and subsequently prepared for histological examination. Paraffin sections of the cerebellar tissue were cut to $5 \mu \mathrm{m}$ with a microtome (Leica 2235 Microtome, Buffalo Grove, IL. USA), mounted and stained on a glass slide with hematoxylin and eosin (H and $\mathrm{E}$ ) or toluidine blue stain [36] for histochemistry examination under a light microscope (Leica DM4M, Brooklyn, NY, USA). Micrographs were captured using Moticam Pro 282A 5.0 MP (Motic images Software Plus 2.0 TWAIN, Hong Kong).

The numbers of necrotic Purkinje cells in the cerebellum were quantified using image analyzer software (Motic images Software Plus 2.0 TWAIN, Hong Kong). Quantification of the necrotic Purkinje cells was done at 400× magnification in ten non-overlapping fields from six different sections obtained from 3 rats from each group. The average values of the necrotic Purkinje cells for the 10 non-overlapping fields were calculated for each section and analyzed with GraphPad Prism. Counting of the necrotic Purkinje cells was done manually with the aid of an image analyzer in a blinded manner by an independent pathologist.

\subsection{Statistical Analysis}

The data obtained from this study were analyzed using unpaired independent student's $t$-test and one-way and two-way ANOVA using GraphPad Prism (GraphPad Prism software, Inc. Version 6.01, San Diego, California, USA). Data were presented as the mean \pm standard error of the mean (SEM), where $p<0.05$ was considered statistically significant.

\section{Results}

\subsection{Induction of $\mathrm{Pb}$ Acetate Toxicity in Rats}

\subsubsection{Effect of $\mathrm{Pb}$ Acetate on Body Weight of Rats during $\mathrm{Pb}$ Toxicity Induction}

In order to evaluate the effect of $\mathrm{Pb}$ acetate on body weight of the experimental rats, two-way ANOVA was employed and the results indicated a statistically significant interaction between the effect of $\mathrm{Pb}$ acetate on body weight and weeks of induction of $\mathrm{Pb}$ toxicity, $(\mathrm{F}(16,125)=3.01, p=0.0003)$. Tukey's post hoc comparison indicated a significant decrease $(p<0.05)$ in body weight in group B, C, $\mathrm{D}$, and $\mathrm{E}$ rats in week 3 and week 4 when compared to the body weight of rats in group $\mathrm{A}$, as shown in Figure 2. 


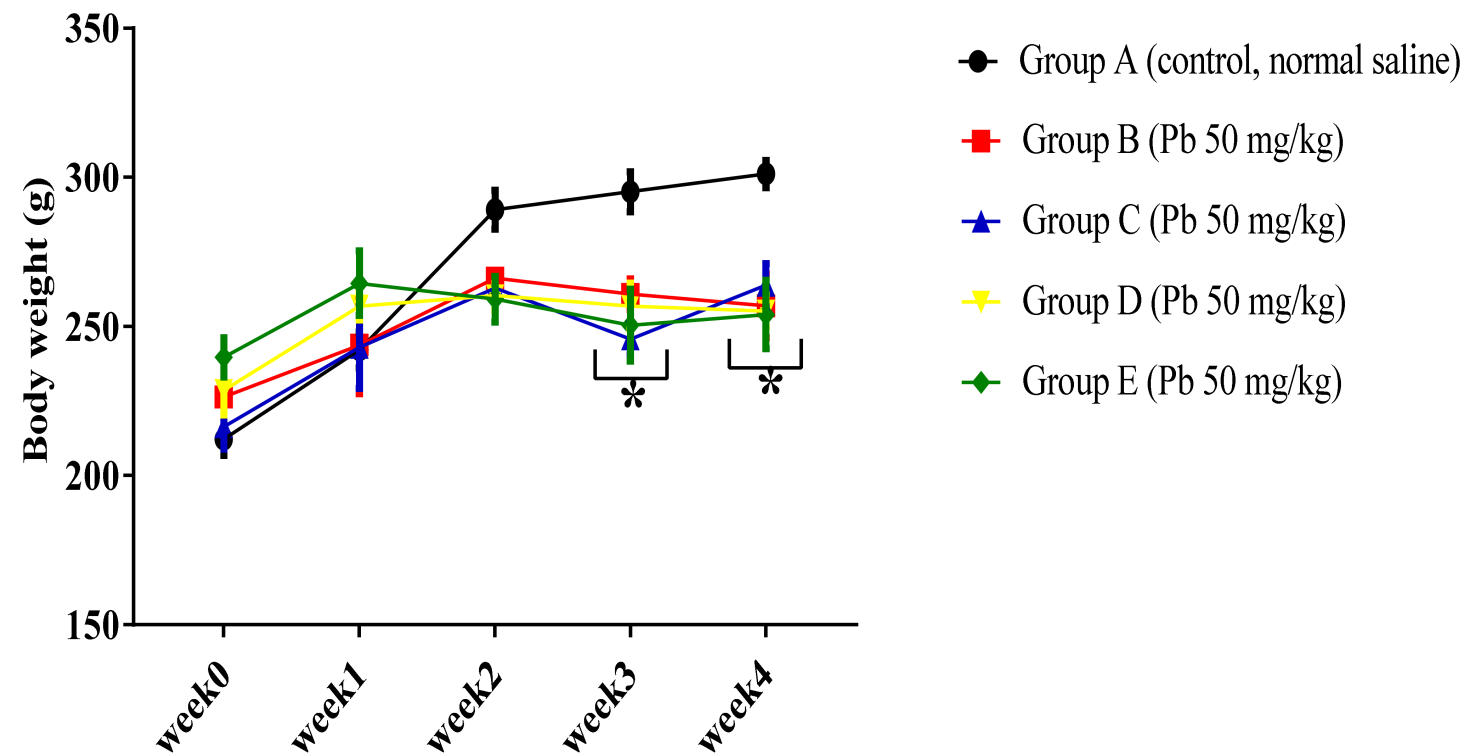

Figure 2. Effect of $\mathrm{Pb}$ toxicity on body weight following four weeks of oral administration $\mathrm{Pb}$ acetate. Data are represented as mean $\pm \operatorname{SEM}(n=6) ;{ }^{*} p<0.05$ vs. control.

\subsubsection{Effect of $\mathrm{Pb}$ Acetate on Motor Score and Coordination in Rats during $\mathrm{Pb}$ Toxicity Induction}

In order to evaluate the effect of oral administration of $\mathrm{Pb}$ acetate on the motor function of rats, the horizontal bar test was performed. The results indicated a statistically significant interaction between treatment effect of oral administration of $\mathrm{Pb}$ acetate and weeks of treatment $(\mathrm{F}(16,125)=2.23$, $p=0.0072)$ in the motor scores among the rat groups. Tukey's post hoc comparison showed a significant decrease $(p<0.05)$ in the motor score of $\mathrm{Pb}$-administered rats regarding their ability to maintain a hand grip balance on the $2 \mathrm{~mm}$ horizontal bar at week 3 and week 4 in group B, C, D, and E rats compared with the motor score of rats in group A, as seen in Figure 3.

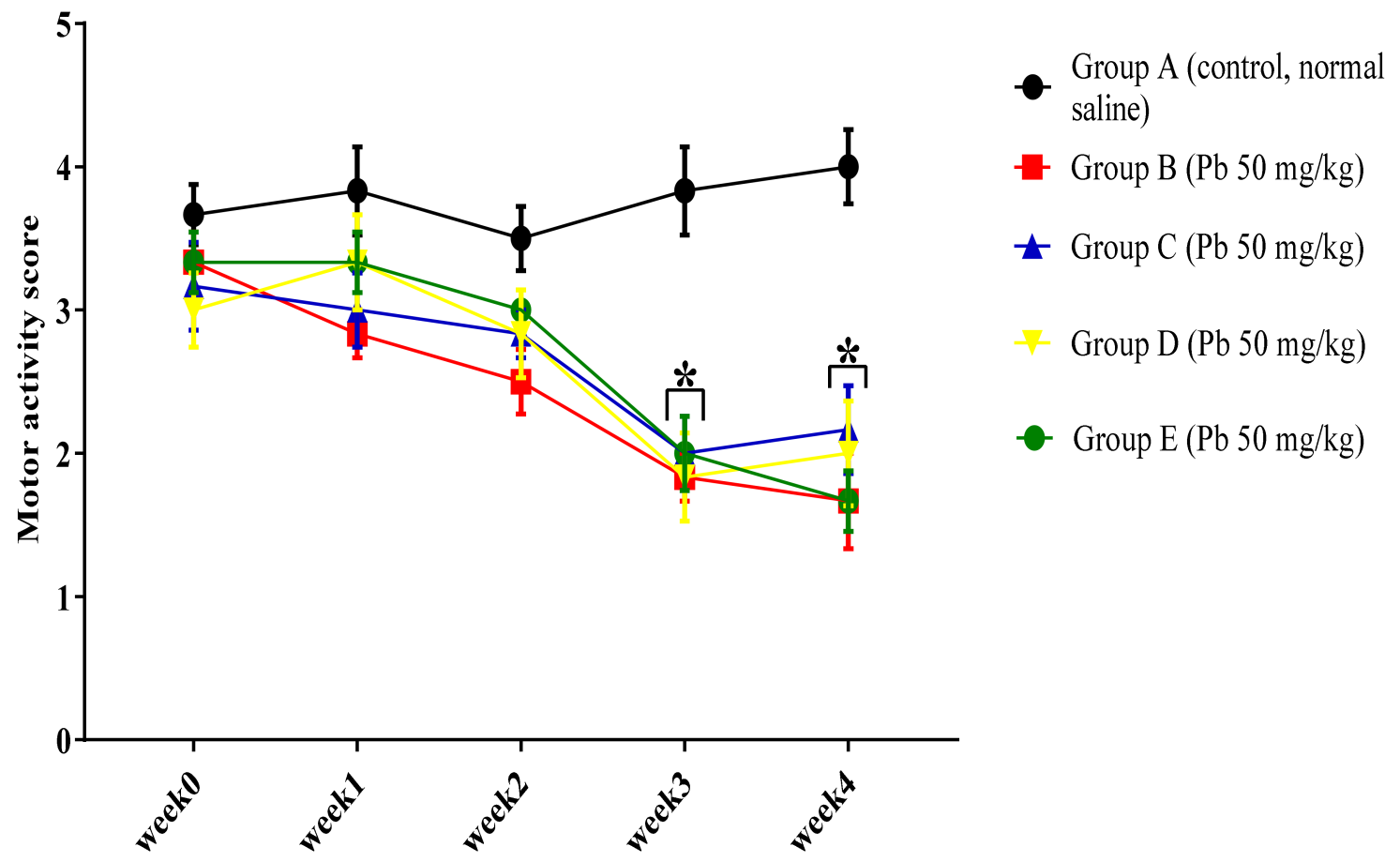

Figure 3. Effect of oral administration of $\mathrm{Pb}$ acetate on motor score of rats during induction of $\mathrm{Pb}$ toxicity. Values are presented as mean $\pm \operatorname{SEM}(n=6) ;^{*} p<0.05$ vs. control. 
3.1.3. Effect of $\mathrm{Pb}$ Acetate on Oxidative Stress Status of Cerebellum in Rats of Control and LTGs during $\mathrm{Pb}$ Toxicity Induction

To confirm the induction of $\mathrm{Pb}$ toxicity in the rats, the oxidative stress status in their cerebellums were assessed through unpaired independent student's t-test.

\section{SOD Activity}

Results from the unpaired independent student's t-test (Figure 4) showed a statistically significant difference in cerebellar SOD activity between the rats of the control group $(M=8.4$, SEM $=0.4)$ and the LTG $(M=4.833$, SEM $=0.3283) ; \mathrm{t}(4)=6.892, p=0.0023$ following oral administration of $\mathrm{Pb}$ acetate.

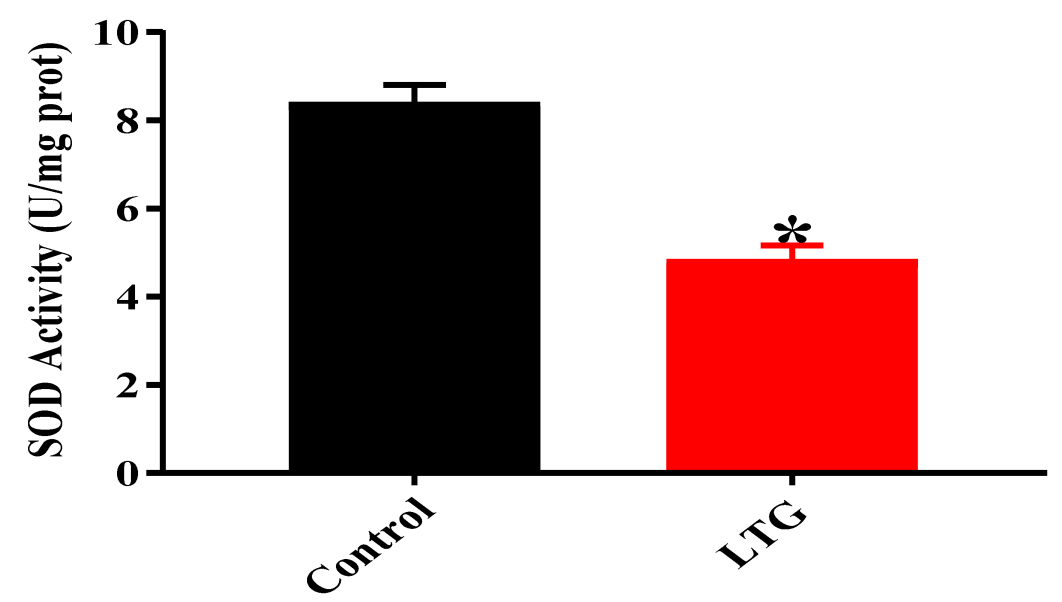

Figure 4. Effect of $\mathrm{Pb}$ acetate administration on $\mathrm{SOD}$ activity in the cerebellums of rats after $\mathrm{Pb}$ toxicity induction. Data are expressed as mean $\pm \operatorname{SEM}(n=3) ;{ }^{*} p<0.005$ vs. control.

MDA Level

Similarly, the results of the unpaired independent student's t-test results, shown in Figure 5, indicated a statistically significant difference in cerebellar MDA levels of rats in the control group $(M=15.4, \mathrm{SEM}=2.794)$ and the LTG $(M=42.19, \mathrm{SEM}=7.979) ; \mathrm{t}(4)=3.169, p=0.0339$ after oral administration of lead acetate for four weeks.

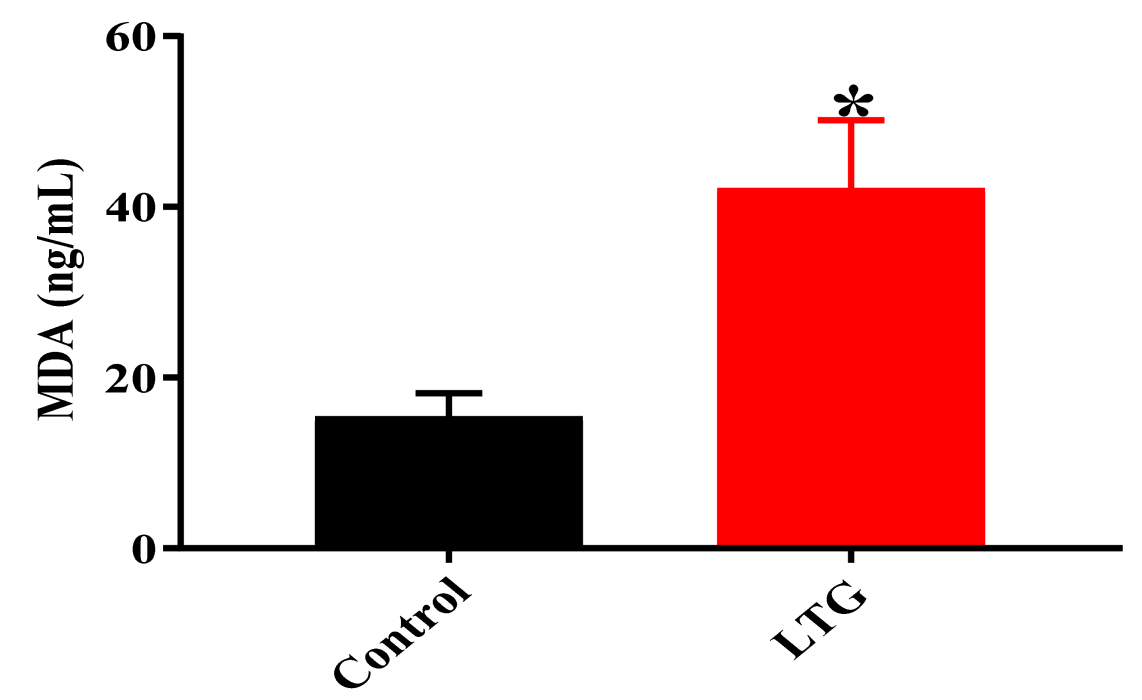

Figure 5. Effect of $\mathrm{Pb}$ acetate administration on MDA levels in the cerebellums of rats after $\mathrm{Pb}$ toxicity induction. Data are expressed as mean $\pm \operatorname{SEM}(n=3) ;{ }^{*} p<0.005$ vs. control. 
3.1.4. Determination of $\mathrm{Pb}$ Concentration in the Cerebellums of Rats in the Control Group and LTG after Pb-Toxicity Induction

To determine the concentration of $\mathrm{Pb}$ in the rats' cerebellums, the ICP-MS technique was used. Independent student's t-test was employed to analyze the difference in $\mathrm{Pb}$ concentration in the cerebellums of rats in the control group and LTG after oral administration of $\mathrm{Pb}$ acetate. The results indicated statistically significant differences in $\mathrm{Pb}$ concentrations in the cerebellums of rats in the control group $(M=0.2, \mathrm{SEM}=0.024)$ and LTG $(M=2.58, \mathrm{SEM}=0.6009) ; \mathrm{t}(4)=3.981, p=0.0164$ (Figure 6).

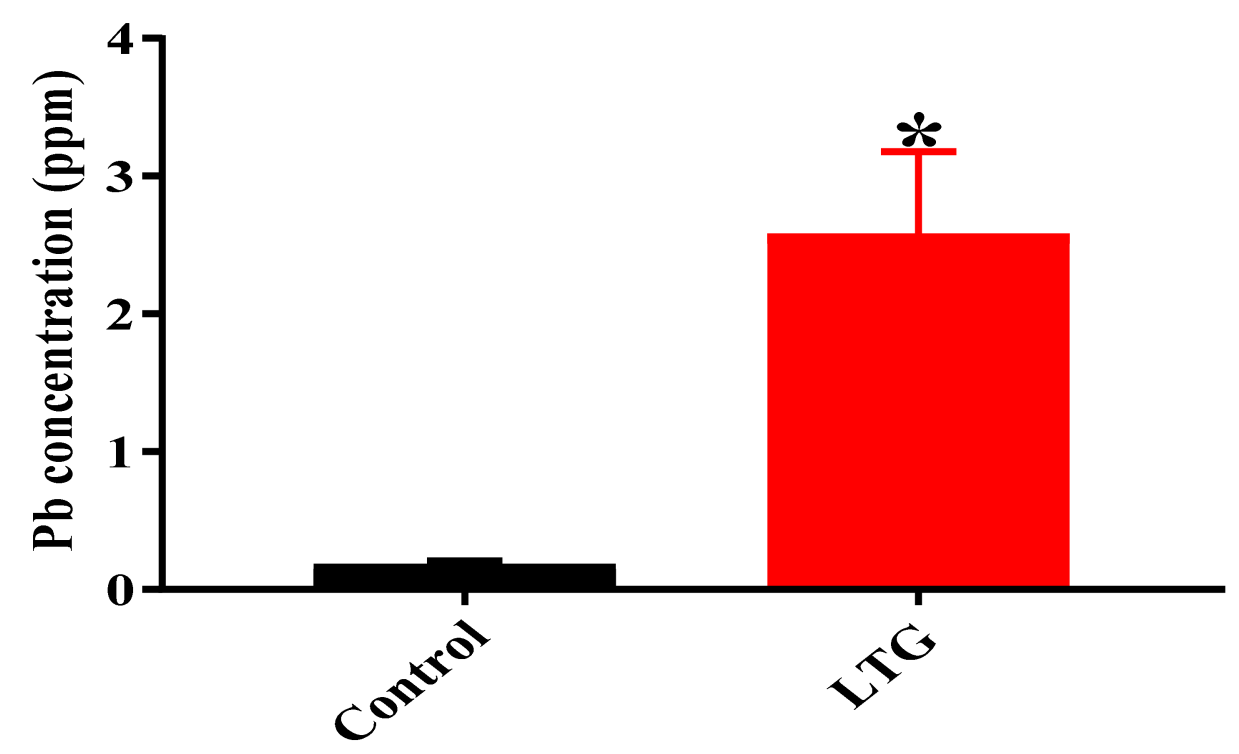

Figure 6. Concentration (ppm) of $\mathrm{Pb}$ in rats' cerebellums after induction of $\mathrm{Pb}$ toxicity for four weeks. Data are represented as mean $\pm \operatorname{SEM}(n=3){ }^{*} p<0.05$ vs. control.

3.1.5. Effect of $\mathrm{Pb}$ Acetate on Histology of Cerebellum of Rats in the Control Group and LTG after the Induction of $\mathrm{Pb}$ Toxicity

Cerebellum Stained with Hematoxylin and Eosin (H and E)

The histopathological examination of the cerebellar tissue of $\mathrm{Pb}$-administered rats using $\mathrm{H}$ and $\mathrm{E}$ stain revealed histological alterations of the cerebellar cortex layers with shrinkage and degeneration of the Purkinje and molecular layer cells with scattered glial cells. The Purkinje cells exhibited darkly stained nuclei with eosinophilic cytoplasm and empty spaces between them, indicating degeneration of the Purkinje cells (Figure 7B) compared with the control rats (Figure 7A).

Further, in order to evaluate the effect of $\mathrm{Pb}$ acetate on the Purkinje cells of the cerebellum, the nonparametric t-test was used. The Mann-Whitney test indicated that the number of degenerated Purkinje cells was significantly greater in the cerebellum of rats in the LTG $(\mathrm{Mdn}=5.5)$ compared to the control group ( $\mathrm{Mdn}=0.73) ; \mathrm{U}=0, p=0.0022$ (Figure 7C). 

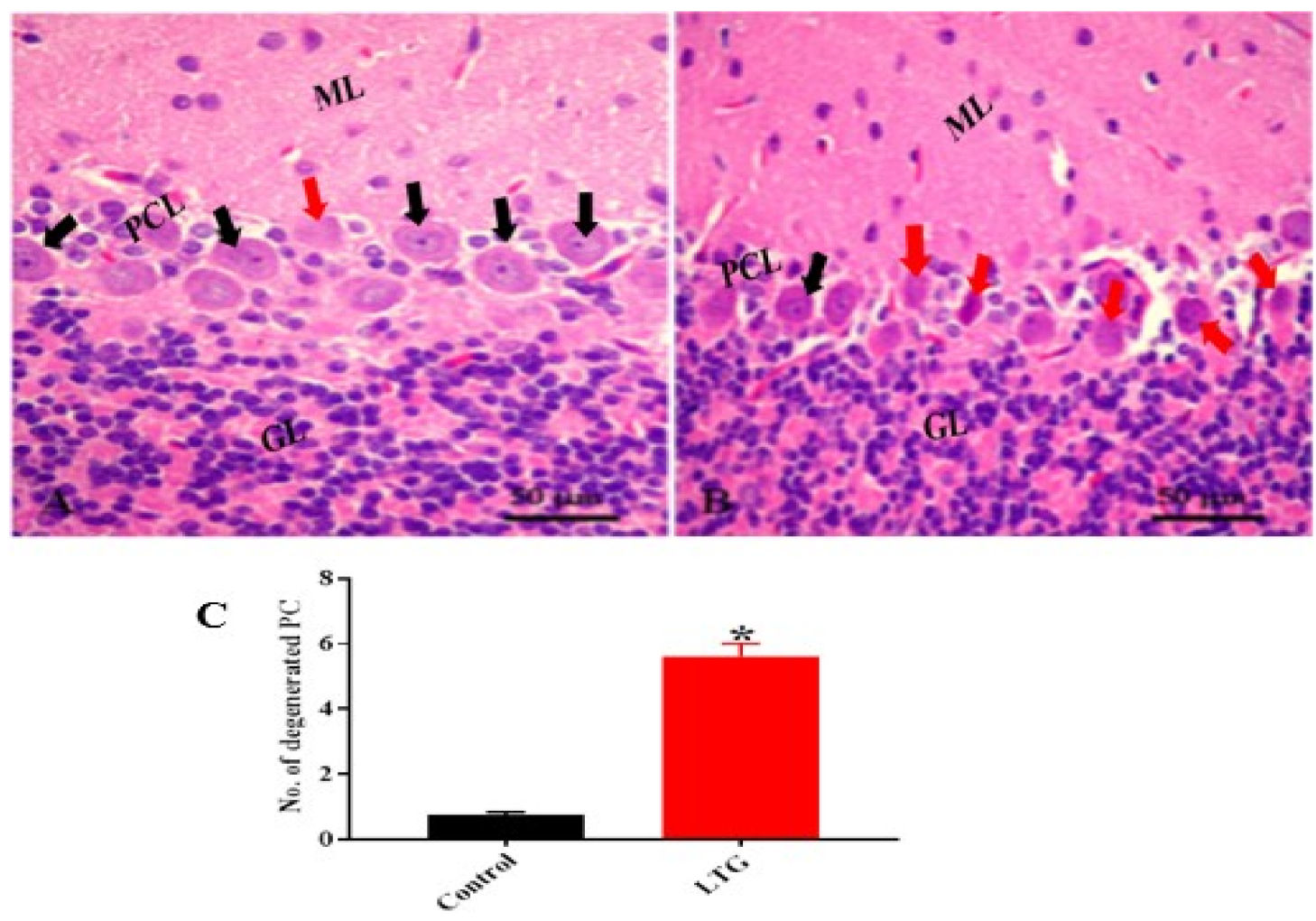

Figure 7. (A) Photomicrograph of control cerebellar cortex showing the layers of the cerebellum: The molecular layer (ML), the middle Purkinje cell layer (PCL) with a large pyriform shape (black arrow), and the inner granular layer (GL) with aggregation of granular cells. (B) Lead-treated group (LTG) showing marked degeneration of Purkinje cells (red arrow). (C) Semi-quantitative representation of degenerated Purkinje cells of the control group and LTG. Data are represented as mean \pm SEM $(n=3){ }^{*} p<0.05$ vs. control. H and E 400×, scale bar $=50 \mu \mathrm{m}$.

Cerebellum Stained with Toluidine Blue

In order to further confirm the neurodegenerative effect of $\mathrm{Pb}$ acetate induction on the cerebellums of rats, toluidine blue staining was also performed. The histological results from the cerebellums of rats in the LTG indicated degeneration of the cells of the molecular layer and distortion of the Purkinje cell layer, with the Purkinje cells having a darkly stained cytoplasm and distorted nuclei with empty space between them, indicating loss of Purkinje cells (Figure 8B) compared with rats in the control group (Figure $8 \mathrm{~A}$ ). 

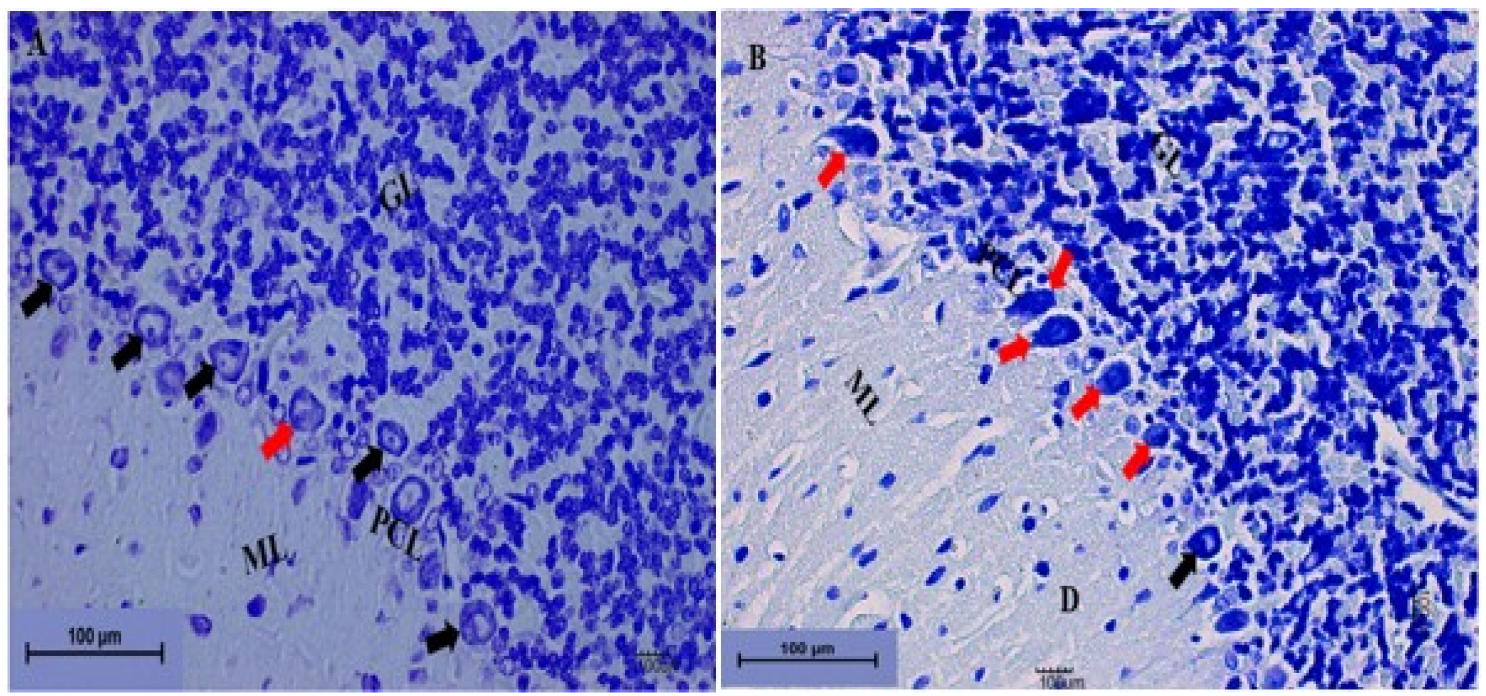

Figure 8. Photomicrograph sections of the cerebellums from the rat groups. (A) Control showing the molecular layer (ML), the granular layer (GL), and the Purkinje cell layer (PCL). The Purkinje cells are shown by the black arrow, with prominent nuclei. (B) LTG showing the molecular layer (ML) with a degenerated area of cells (D) and Purkinje cells with darkly stained cytoplasm and distorted nuclei leaving spaces between them (red arrow). The granular layer (GL) indicates deeply stained cells with vacuolation (toluidine blue $200 \times$, scale bar $=100 \mu \mathrm{m}$ ).

Effect of $\mathrm{Pb}$ Acetate on the Weight of the Cerebellums of Control Group and LTG Rats after Pb-Toxicity Induction

An unpaired t-test was employed to evaluate the effect of $\mathrm{Pb}$ acetate administration on cerebellar weight in rats of the control group and LTG. The results showed statistically significant differences in the cerebellar weights of rats in the control group $(M=0.5333$, SEM $=0.02418)$ when compared to LTG rat $(M=0.4033$, SEM $=0.1706) ; \mathrm{t}(10)=4.393, p=0.0013$ (Figure 9).

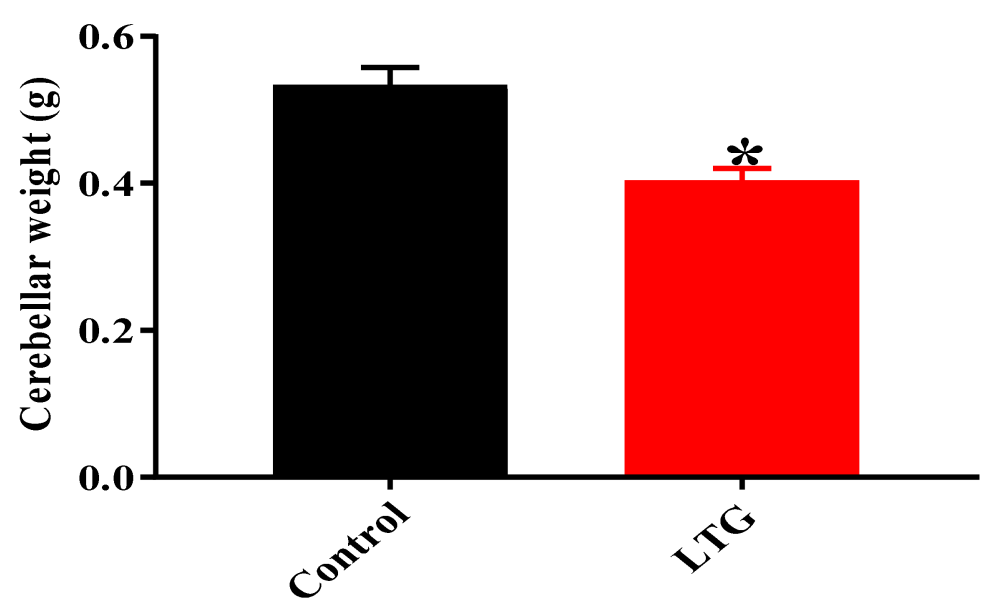

Figure 9. Effect of $\mathrm{Pb}$ acetate on cerebellar weights of rats of the control group and LTG. Data are represented as mean $\pm \operatorname{SEM}(n=6){ }^{*} p<0.05$ vs. control.

\subsection{Treatments of Pb Acetate-Induced Rats with Curcumin}

\subsubsection{Effect of Curcumin on the Body Weight of Pb-Induced Rats}

Two-way ANOVA results showed a statistically significant interaction between the effect of curcumin on the body weight of rats and the weeks of administration $(F(24,180)=3.242, p=0.0001)$. Tukey's post hoc test indicated a significant decrease $(p<0.05)$ in the body weight of rats in the RC and 
Cur100 and Cur200 groups in week 3, week 4, week 5, week 7, and week 8 when compared to the body weight of rats in the control group, as shown in Figure 10.

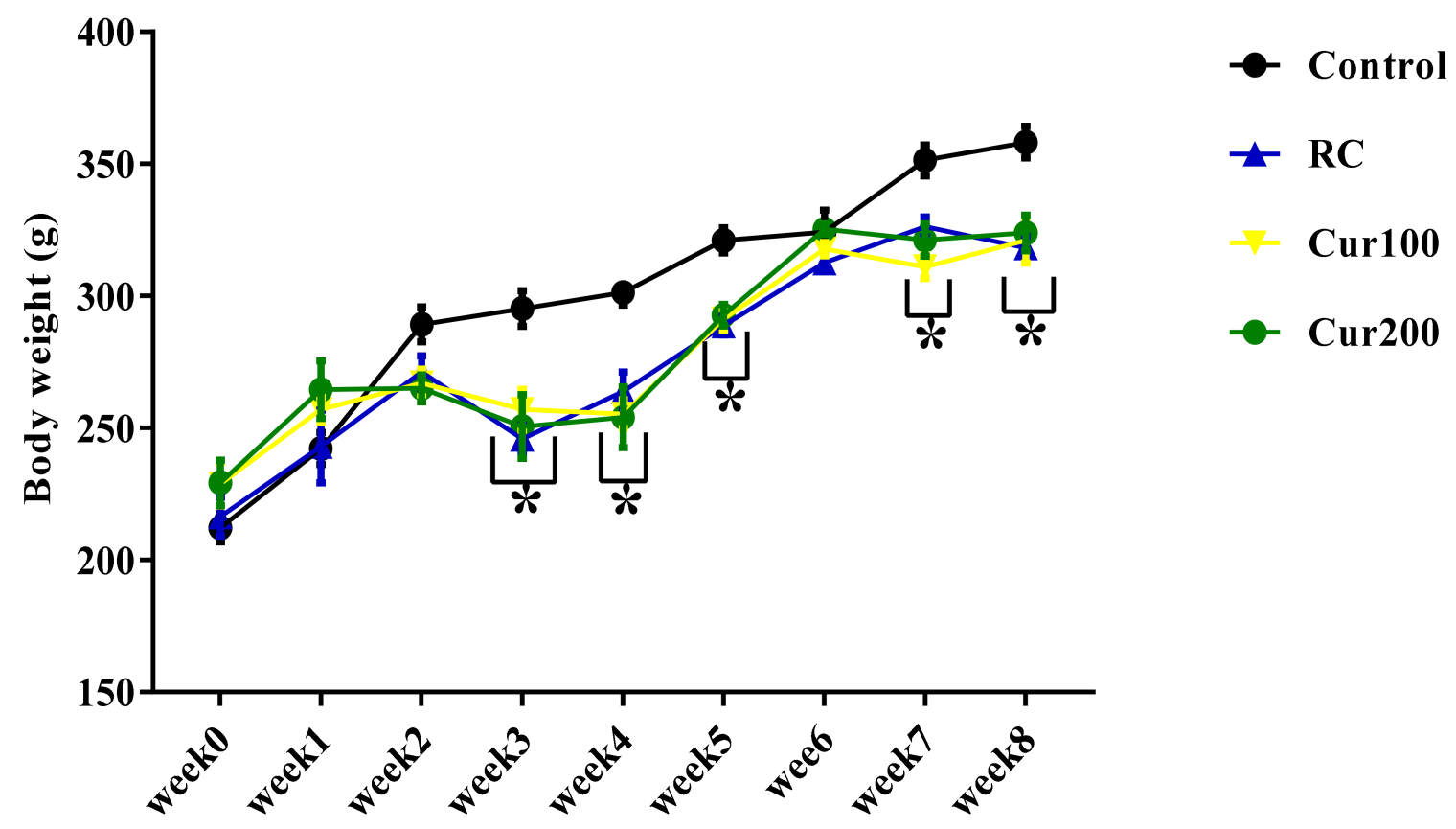

Figure 10. Effect of oral administration of curcumin on body weight of $\mathrm{Pb}$ acetate-induced rats. Data are represented as mean $\pm \operatorname{SEM}(n=6) ;{ }^{*} p<0.05$ vs. control.

3.2.2. Curcumin Ameliorates Pb-Induced Alteration of Motor Coordination of Rats in the Horizontal Bar Test

The two-way ANOVA results showed a statistically significant interaction between the effect of oral administration of curcumin and weeks of treatment $(F(24,180)=2.448, p=0.0004)$ in the motor scores of $\mathrm{Pb}$-induced rats treated with curcumin (Figure 11). Tukey's post hoc comparison indicated a statistically significant decrease $(p<0.05)$ in the motor score of rats in the RC, Cur100, and Cur200 groups regarding their ability to maintain a hand grip balance on the $2 \mathrm{~mm}$ horizontal bar in week 3 , week 4, week 5, and week 6 when compared to the control group of rats. Additionally, Tukey's post hoc test further revealed a significant increase $(p<0.05)$ in the motor score of rats in the control group in week 7 and week 8 compared to the motor score of rats in the RC group. 


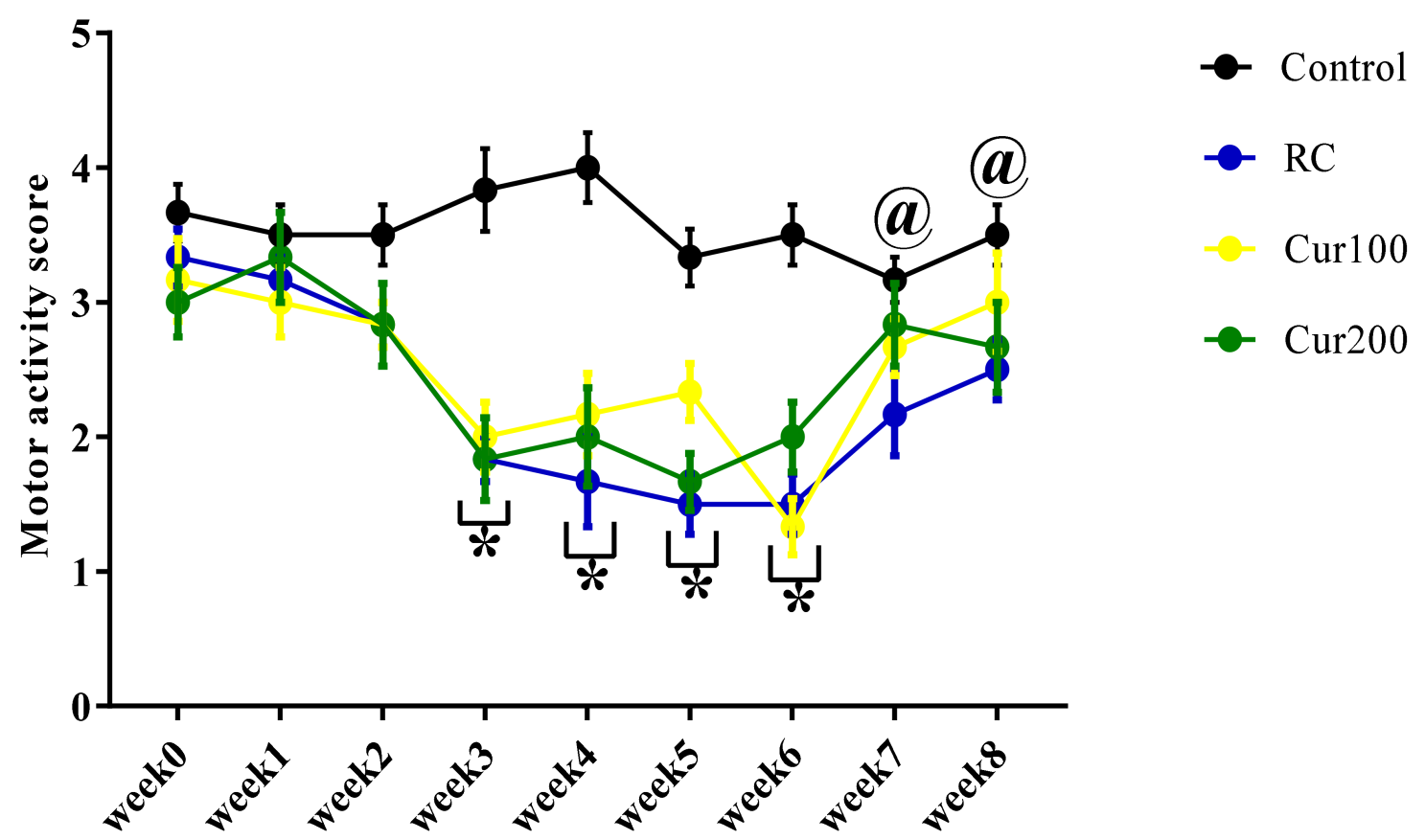

Figure 11. Effect of oral admiration of curcumin on $\mathrm{Pb}$-induced rats in the horizontal bar test. Values are presented as mean $\pm \operatorname{SEM}(n=6){ }^{*} p<0.05$ vs. control, ${ }^{\circledR} p<0.05$ vs. RC.

\subsubsection{Curcumin Reverse Pb-Induced Oxidative Stress in Rats' Cerebellums}

In order to assess the antioxidant properties of curcumin on Pb-induced oxidative stress in rats, the cerebellar homogenates of the rats were analyzed for SOD activity and MDA levels.

\section{SOD Activity}

As shown in Figure 12, the one-way ANOVA results revealed a statistically significant differences in SOD activity in the cerebellums of different experimental rats groups $(\mathrm{F}(3,8)=3.768, p=0.0493)$. Tukey's post hoc test showed a statistically significant decrease in SOD activity in the cerebellums of the $R C$ rats $(5.167 \pm 0.133, p=0.0443)$ when compared with the control group of rats $(8.4 \pm 0.4)$. 


\section{Cerebellum}

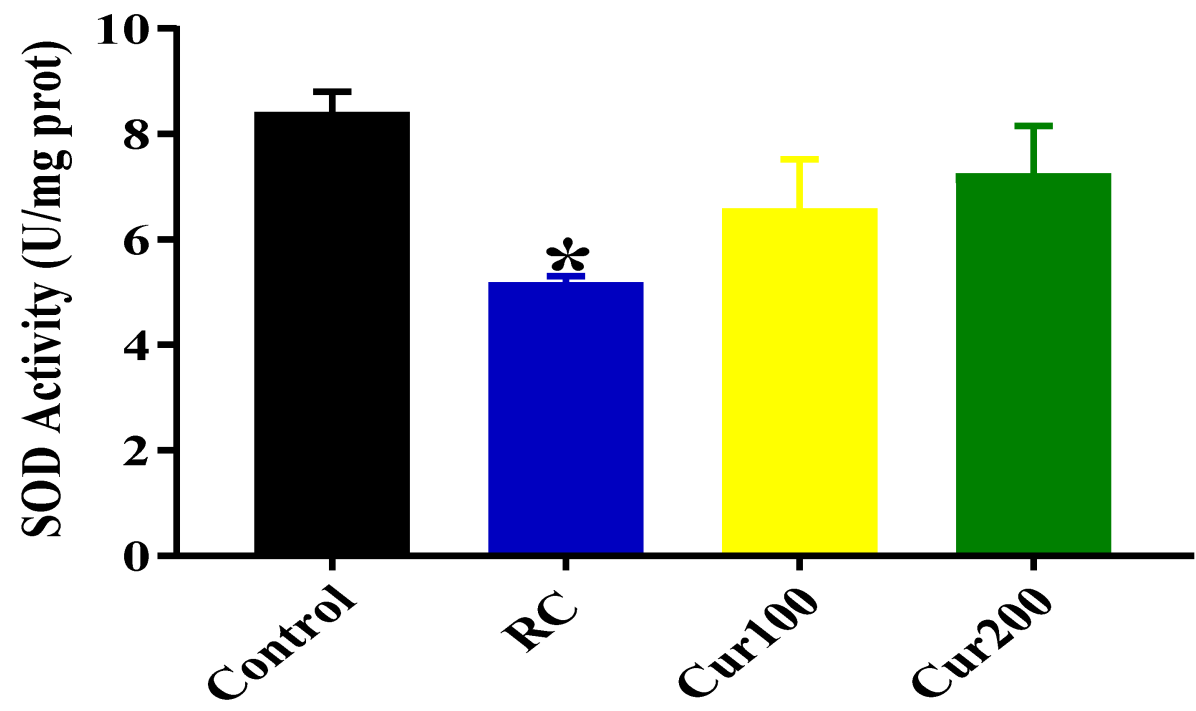

Figure 12. Effect of curcumin on superoxide dismutase (SOD) activity in the cerebellums of Pb-induced rats. Data are expressed as mean $\pm \operatorname{SEM}(n=3) ;{ }^{*} p<0.05$ vs. control.

MDA Level

The one-way ANOVA result showed a statistically significant difference in MDA levels in the cerebellums of all rat groups $(\mathrm{F}(3,8)=5.844, p=0.0205)$. Tukey's comparison test revealed a significant increase in the MDA levels in the cerebellums of rats from the RC group $(22.78 \pm 1.579, p=0.0153)$ compared to the control group of rats $(15.4 \pm 1.062)$, as shown in Figure 13.

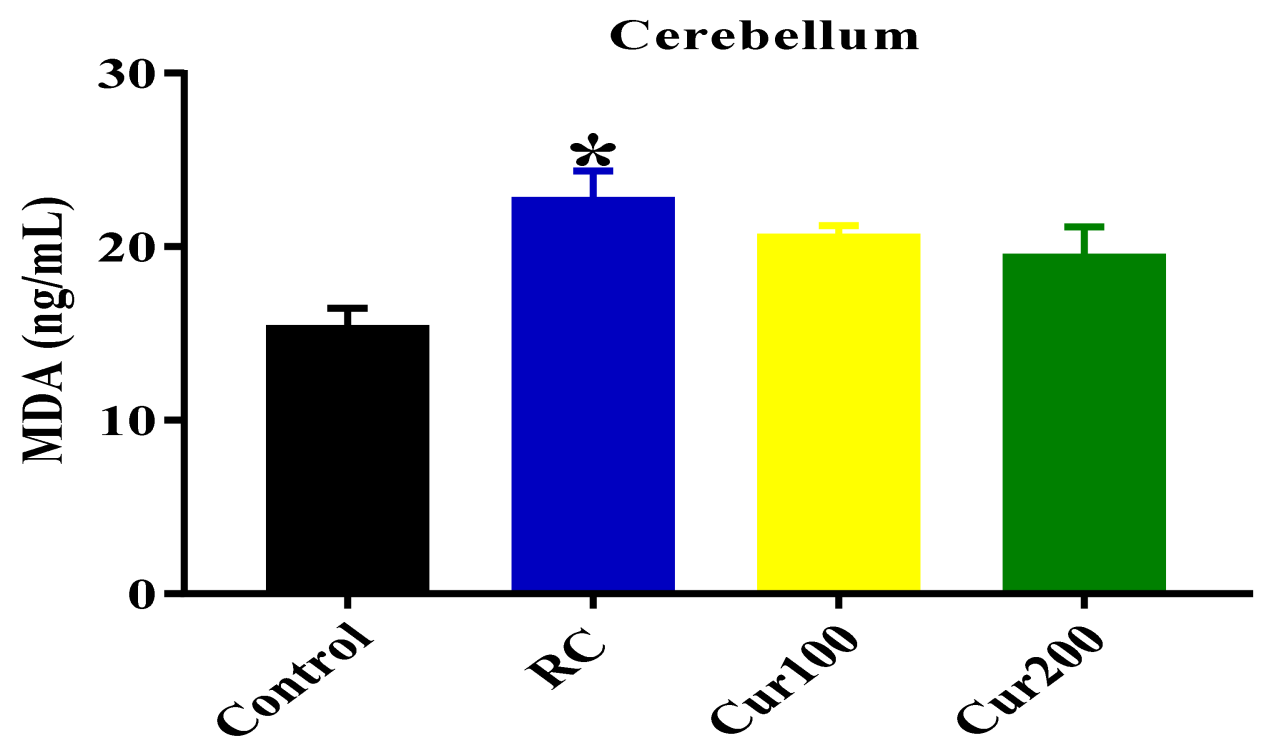

Figure 13. Effect of curcumin on malondialdehyde (MDA) levels in the cerebellums of $\mathrm{Pb}$-induced rats. Data are expressed as mean $\pm \operatorname{SEM}(n=3) ;{ }^{*} p<0.05$ vs. control.

\subsubsection{Chelating Potentials of Curcumin on Pb-Induced Toxicity in Rats}

The results obtained from the ICP-MS analysis were subjected to one-way ANOVA to evaluate the mean $\mathrm{Pb}$ concentration in the cerebellums of rats in the control, RC, Cur100, and Cur200 groups. Results obtained showed statistically significant differences in $\mathrm{Pb}$ concentrations in the cerebellums of the different rat groups $(\mathrm{F}(3,8)=8.61, p=0.0069)$. Tukey's post hoc comparison indicated significant 
decreases in $\mathrm{Pb}$ concentration in the cerebellums of rats in the control $(0.1828 \pm 0.02414, p=0.0001)$, Cur100 (0.6319 $\pm 0.1545, p=0.0014)$, and Cur200 $(0.4848 \pm 0.08147, p=0.006)$ groups compared to rats in the RC group (Figure 14).

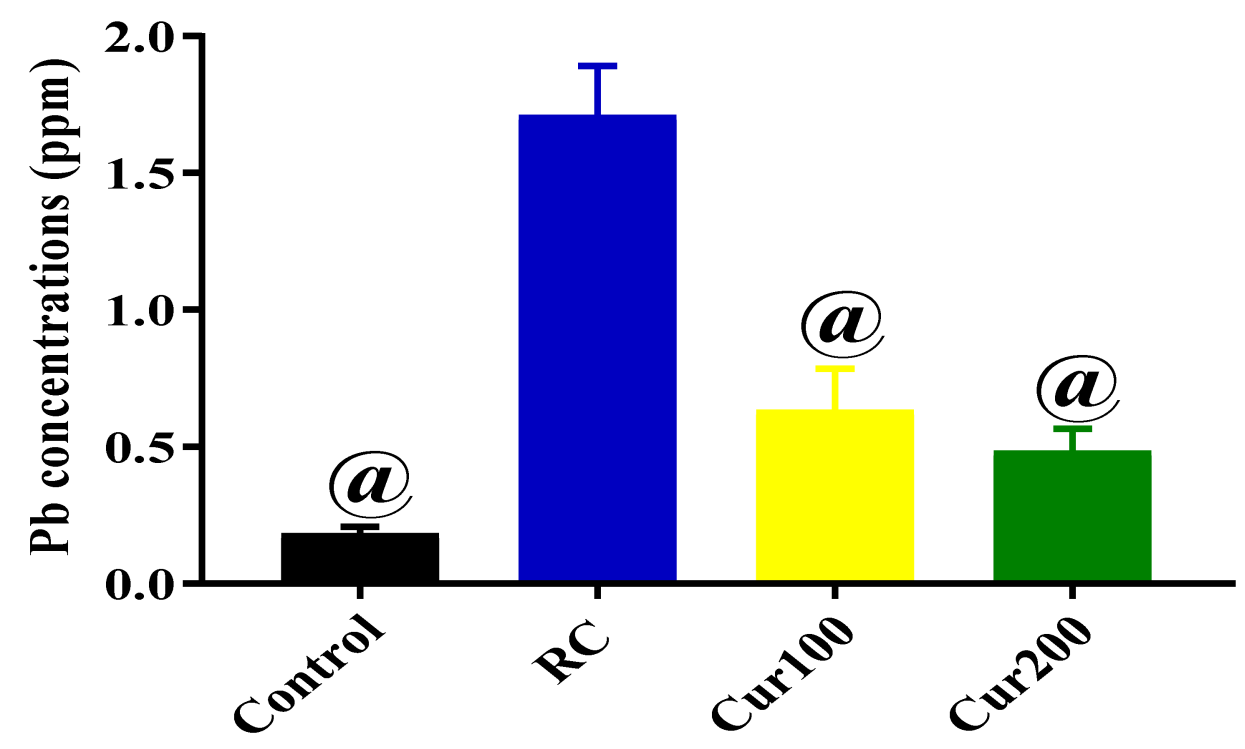

Figure 14. Concentration of $\mathrm{Pb}$ in rats' cerebellums after oral administration of curcumin and withdrawal of $\mathrm{Pb}$ acetate for four weeks. Data are represented as mean \pm SEM $(\mathrm{n}=3)$; ${ }^{\circledR} p<0.05 \mathrm{vs}$. RC.

\subsubsection{Curcumin Attenuates Pb-Induced Cerebellar Damage in Rat's Cerebellum}

\section{$\mathrm{H}$ and E Staining}

The histology results from the cerebellums of rats in the RC group stained with $\mathrm{H}$ and $\mathrm{E}$ after withdrawal of $\mathrm{Pb}$ acetate indicated no recovery when compared to rats in the control group (Figure 15A). The RC group cerebellums revealed eosinophilic Purkinje cells with dark and irregular nuclei, with the molecular layer appearing to have scattered glial cells with perineural spaces; the granular layer appeared to have a normal histological appearance (Figure 15B).

Oral administration of curcumin for four weeks attenuated the pathological changes in the cerebellums of rats in the Cur100 (Figure 15C) and Cur200 (Figure 15D) groups. In addition, semi-quantitative analysis of the Purkinje cells of the cerebellums revealed statistically significant differences in degenerated Purkinje cells of the experimental rats $(\mathrm{H}(3)=19.75, p=0.0002)$ with a mean rank of 3.583 for the control rats, 21.5 for RC rats, 13.83 for Cur100 rats, and 11.08 for Cur200 rats. Dunn's multiple comparison test further showed statistically significant increases $(4.333 \pm 0.2246$, $p=0.0001)$ in degenerated Purkinje cells in the cerebellums of RC rats compared to the rats in the control group (Figure 15E). 


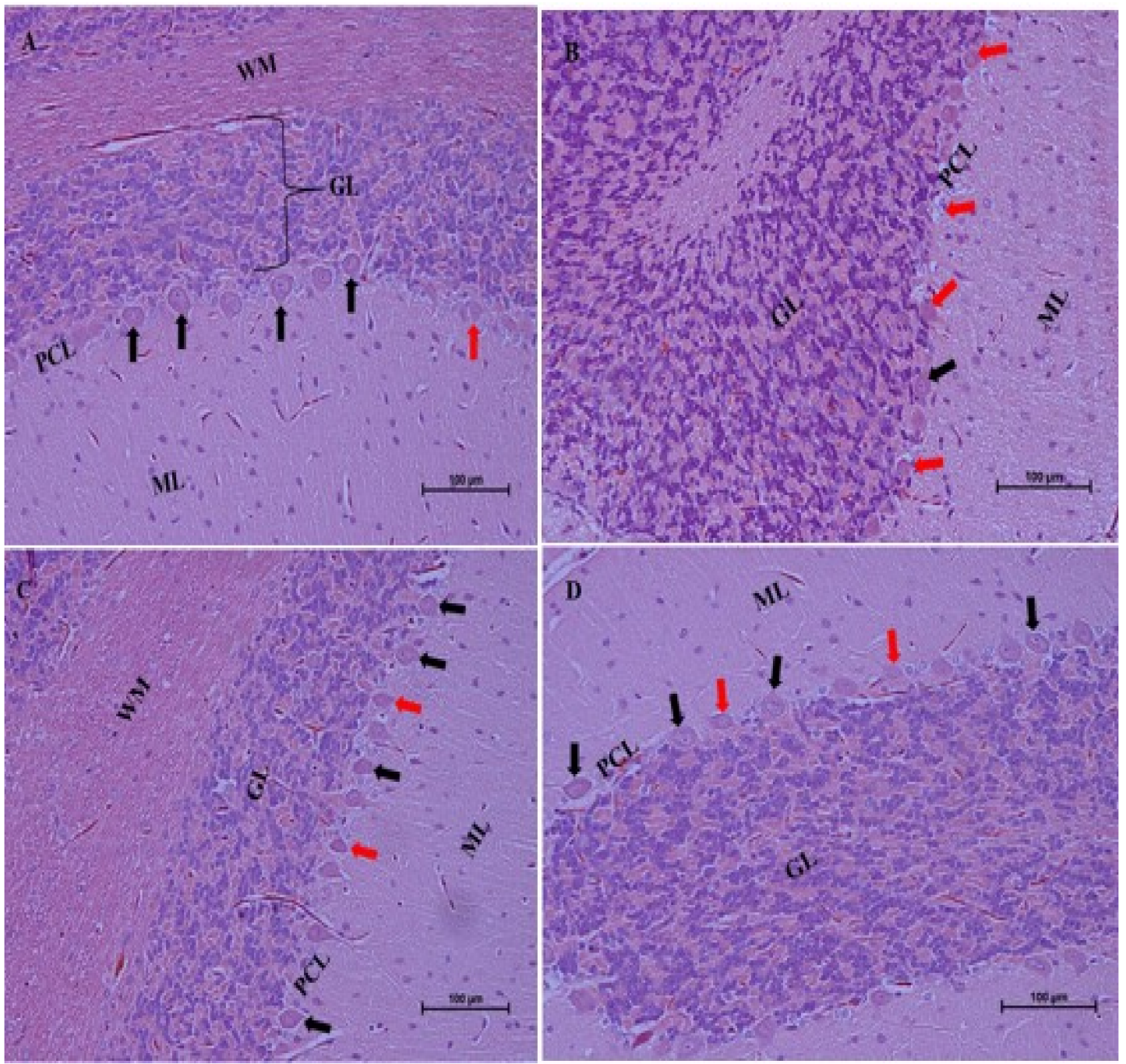

$\mathbf{E}$

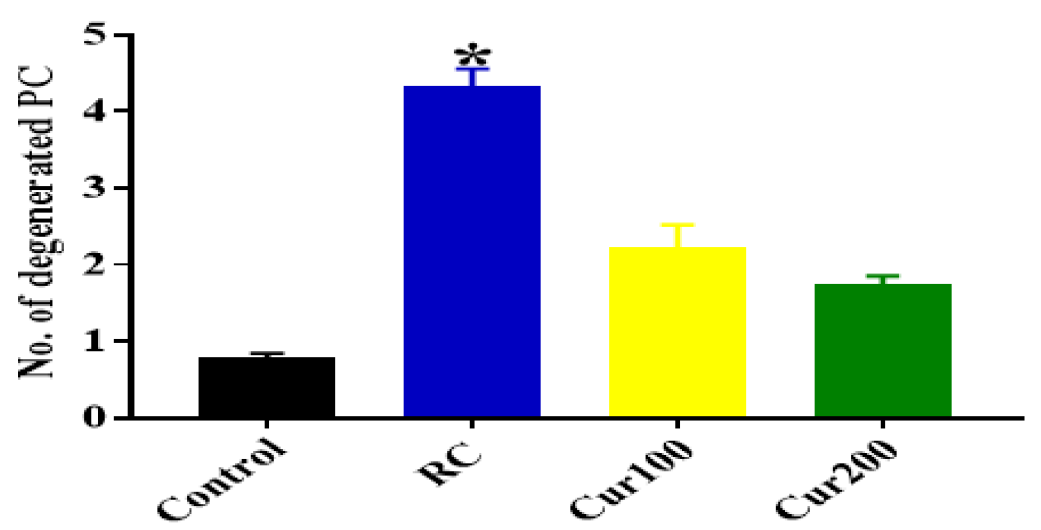

Figure 15. Photomicrograph sections of the cerebellums of the rat groups. (A) Control group indicating layers of the cerebellar cortex, the molecular layer (ML) with glial cells, the middle Purkinje cell layer (PCL) with the Purkinje cells having a large pyriform shape (black arrow), white matter (WM), and the inner granular layer with aggregation of granular cells (GL). (B) RC showing eosinophilic Purkinje cells with irregular dark cytoplasm (red arrow) and scattered glial cells in the molecular layer (ML). (C) Cur100 showing the Purkinje cells with prominent nuclei and a regular shape (black arrow); the molecular and granular layers appear normal. (D) Cur200 showing normal pyriform-shaped Purkinje cells with prominent nuclei (black arrow) and normal granular and molecular layers. (E) Semi-quantitative representation of degenerated Purkinje cells in different rat groups. Data are represented as mean \pm $\operatorname{SEM}(n=3) ;{ }^{*} p<0.005$ vs. control. H and E 200×, scale bar $=100 \mu \mathrm{m}$. 


\section{Toluidine Blue Staining}

The photomicrograph sections from the cerebellums of the control group of rats indicated normal histological structure of the cerebellum with the three layers of the cerebellar cortex. The Purkinje cells appeared to have regular and prominent central nuclei. The granular and molecular layers showed normal cells with darkly stained nuclei (Figure 16A). Photomicrograph sections from the cerebellums of the RC rats revealed alterations in the Purkinje cell layer, with the Purkinje cells appearing to have darkly stained cytoplasm with irregular nuclei. The molecular layer showed scattered glial cells, although the granular layer appeared to be normal (Figure 16B).

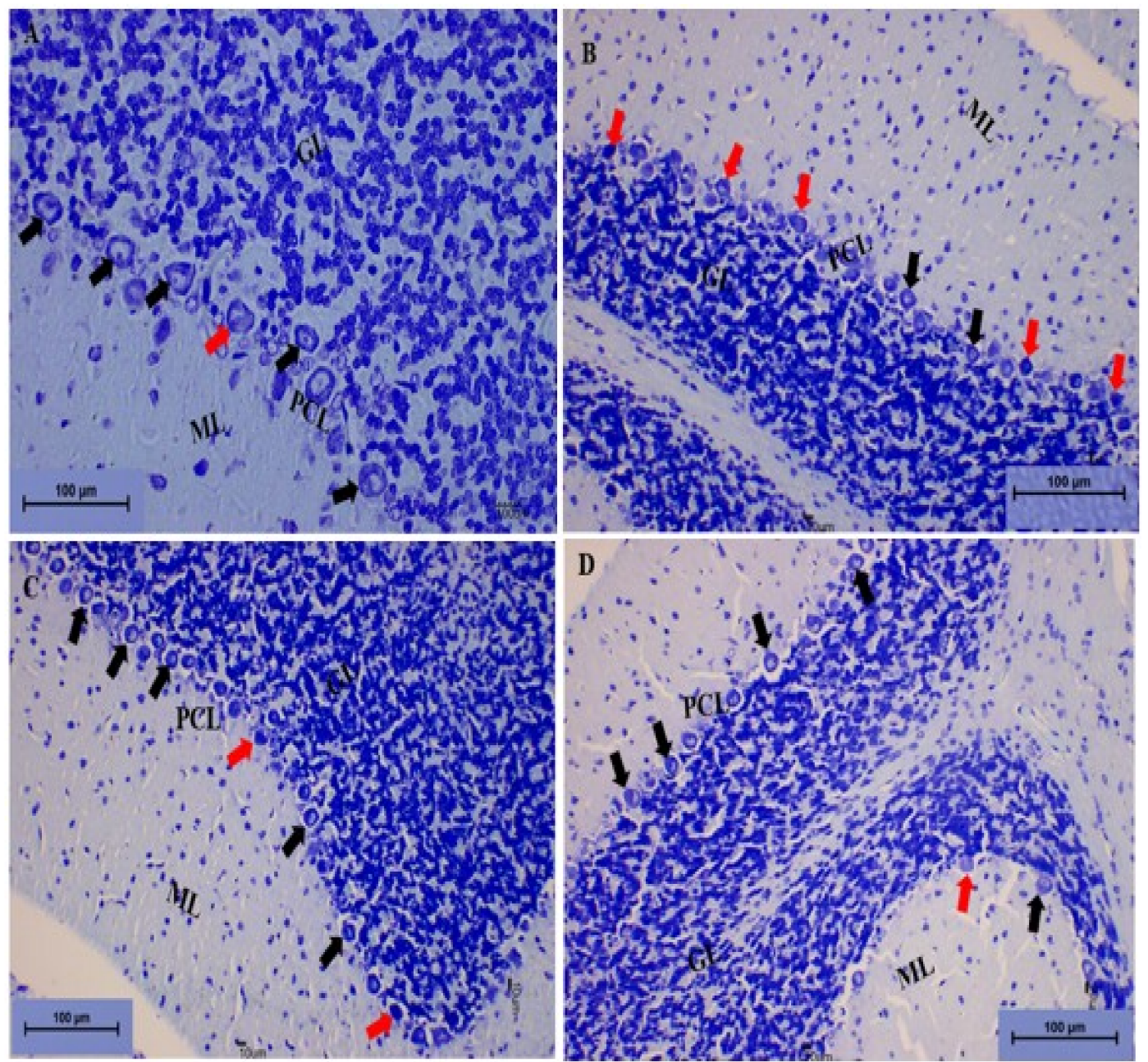

Figure 16. Photomicrograph sections of the cerebellums from the different rat groups. (A) Control group showing the white matter (W) and the three layers of the cerebellar cortex: The molecular layer (ML), the granular layer (GL), and the Purkinje cell layer (PCL) with the Purkinje cells (black arrow) showing prominent nuclei. (B) RC showing the Purkinje cells having deeply stained cytoplasm with distorted shapes (red arrow) and the molecular layer showing scattered glial cells (ML). (C) Cur100 and (D) Cur200 showing the restoration of the molecular layer (ML) and granular layer (GL); the Purkinje cell layer (PCL) appears to be arranged in a linear pattern with the Purkinje cells (black arrow) having prominent nuclei and a regular shape. Toluidine blue, 200×, scale bar $=100 \mu \mathrm{m}$.

The photomicrograph section from the Cur100 and Cur200 showed restoration of the Purkinje cell layer with healthy Purkinje cells. The molecular and granular layers appeared to be normal with normal cells (Figure 16C,D). 
Effects of Curcumin Administration on Cerebellar Weight

One-way ANOVA revealed statistically significant differences in cerebellar weights between the groups of rats $(\mathrm{F}(3.20)=3.195, p=0.457)$. Tukey's post hoc comparison revealed a statistically significant decrease in cerebellar weight of the RC group of rats $(0.4617 \pm 0.01778, p=0.0486)$ compared to the control group, as shown in Figure 17.

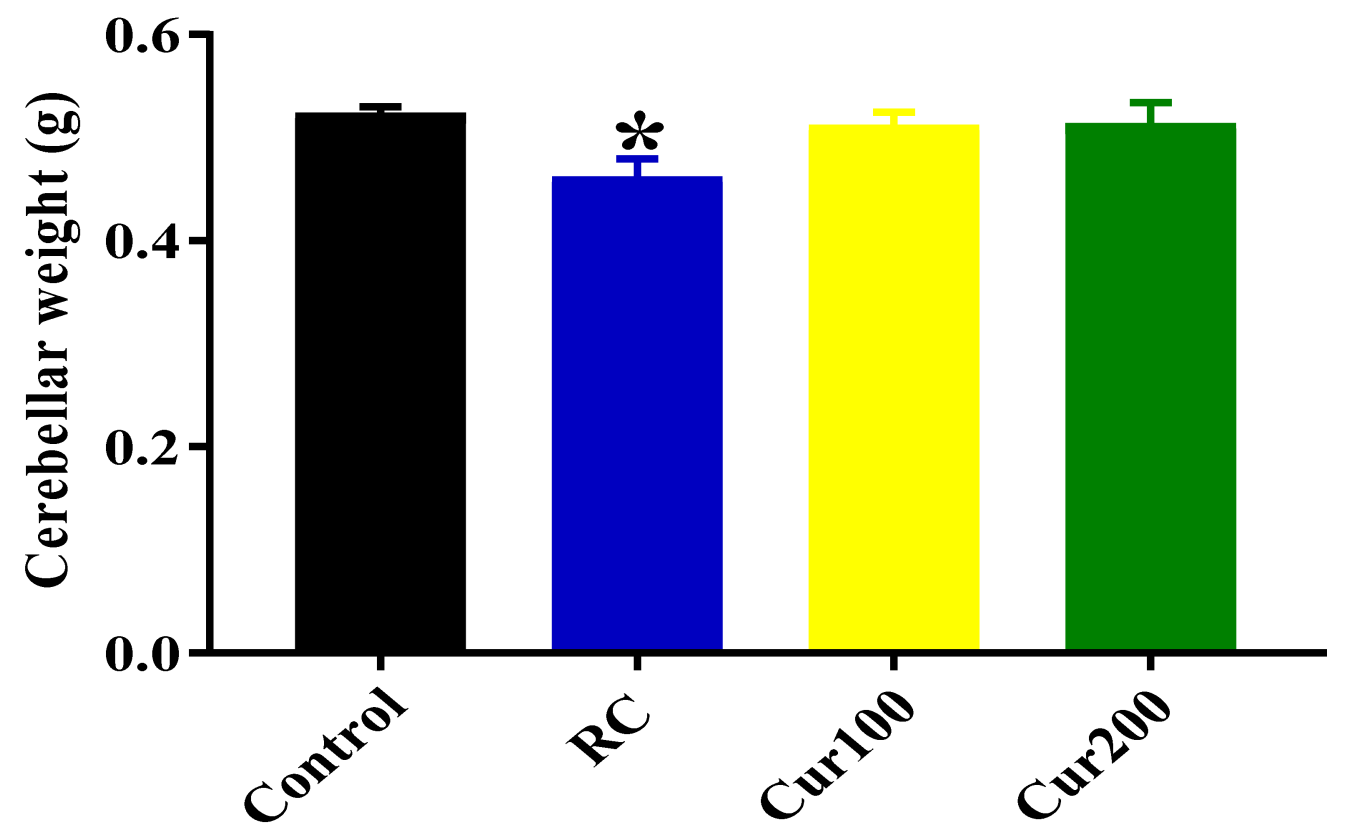

Figure 17. Effect of curcumin administration on cerebellar weights of $\mathrm{Pb}$-induced rats. Data are represented as mean $\pm \operatorname{SEM}(n=6) ;^{*} p<0.05$ vs. control.

\section{Discussion}

Preceding studies have documented the toxic effects of $\mathrm{Pb}$ on biological systems resulting in several pathologies and clinical implications with morbidity on almost all organs, with the brain, kidney, and liver serving as primary targets $[18,37,38]$. These pathological alterations may include increased oxidative stress [9], neurological deficits [39], decreased motor coordination, and cognitive deficits [40,41]. Alterations in astrocyte maturation, degeneration of neural cells [39,41], renal dysfunction, degenerative changes in tubular epithelium, and hepatotoxicity [2,42] were also reported in $\mathrm{Pb}$ poisoning, both in humans and different rodent species. In the present study, a rat model was used to investigate the therapeutic potentials of curcumin on the fundamental mechanisms of motor dysfunction and neurodegeneration caused by $\mathrm{Pb}$ toxicity. The $\mathrm{Pb}$-induced rats developed a remarkable deficiency in the cerebellum-dependent horizontal bar test for motor function, increased oxidative stress, marked degeneration of cells in molecular and Purkinje cell layers of the cerebellum, and high concentrations of $\mathrm{Pb}$ in their cerebellums. However, treatment with curcumin, irrespective of the dose given, attenuated the aforementioned alterations and aberrations caused by $\mathrm{Pb}$ acetate-induced toxicity in the rats.

Worthy to note in this study is the choice of male Sprague Dawley rats for all the experimentations. As female sex hormones, such as estrogen, prolactin, and progesterone, may influence cognitive function, emotion, and motor behavior in rats because their cyclical hormonal changes usually come with mood swings. Hence, female rats were less preferred by the authors for pharmacological testing of phytochemical substances like curcumin due to the potential for confounding factors [43-45]. Therefore, healthy male Sprague Dawley rats were used in this study to evaluate the neurotherapeutic effects of oral administration of curcumin on $\mathrm{Pb}$-induced toxicity of motor function and coordination. 
Coordination of motor behavior and cognitive function depend on the integrity of the nervous system and core psychological functions of the animals $[33,46]$. The cerebellum is a delicate structure that is vulnerable to intoxication and poisoning. The Purkinje cells are particularly susceptible to injury after exposure to environmental toxins such as $\mathrm{Pb}$ [47]. Further, the cerebellum plays a vital role in the unification of motor and sensory functions; any lesion on the cerebellum may result in deterioration of motor coordination and balance [48]. In this study, a decrease in motor score on the horizontal bar test was observed in $\mathrm{Pb}$-induced rats, which is in agreement with the previous works documented by Nehru and Sidhu [49], Barkur and Bairy [50], and Sabbar et al. [51], who also reported a decrease in cognitive and motor functions in rat models regarding Pb toxicity. Mason et al. [7] also reported that $\mathrm{Pb}$ exposure affected motor function, such as the deficits seen in visuomotor coordination in adult $\mathrm{Pb}$ workers and children exposed to $\mathrm{Pb}$. The mechanism in which $\mathrm{Pb}$ executes this decrease in motor function could be due to its ability to induce oxidative stress, as seen in rats exposed to $\mathrm{Pb}[6]$. However, the present study observed an increase in the motor score of rats treated with curcumin, regardless of the dose given. Moore et al. [52], also observed similar findings and attributed it to the antioxidant and anti-inflammatory properties of curcumin. Chongtham and Agrawal [53] also reported that curcumin ameliorated disease symptoms in a Drosophila model of Huntington disease (HD). However, supplementation of diet with curcumin for 12 weeks in a healthy aging population did not influence motor performance [54].

Alterations of oxidative status, either by overproduction of oxidants or deficits in antioxidant activity, could be one of the direct consequences of $\mathrm{Pb}$ toxicity and poisoning in living organisms [6]. Preceding studies indicate that oxidative stress is linked to the pathogenesis of $\mathrm{Pb}$ toxicity, resulting in lipid peroxidation [6], neurodegeneration [55], oxidation of hemoglobin [56], and impairment of fundamental biological cellular processes, such as cell adhesion, intra- and inter cellular signaling, ionic transportation, enzyme regulation, neurotransmitter release, and apoptosis [18]. The fundamental oxidants that play a vital role in redox reactions include hydroxyl radicals $(\mathrm{OH})$, hydroxyl anions $\left(\mathrm{OH}^{-}\right)$, hydrogen peroxide $\left(\mathrm{H}_{2} \mathrm{O}_{2}\right)$, nitric oxide (NO), and peroxynitrite $\left(\mathrm{ONOO}^{-}\right)$[57]. MDA or thiobarbituric acid-reactive species (TBARS) are the end products of lipid peroxidation that play a vital role in lipid membrane damage in cells due to increased reactive oxygen species (ROS) [6]. The present study revealed an increased level of MDA and decreased SOD activity in the cerebellum of Pb-induced rats. However, these alterations were ameliorated by treatment with curcumin, irrespective of the dose given. These findings were in agreement with previous studies that have reported the antioxidant properties of curcumin [58-60].

Inductive-coupled plasma mass spectrometry (ICP-MS) is a robust technique for the molecular analysis of elements and physiochemical compounds, using separation techniques that make it suitable for detecting elements in pharmaceutical research and for specific investigations of elements present in molecules [61]. ICP-MS is a multi-element system technique in the analysis of biological fluids with greater sensitivity and selectivity when compared to inductive-coupled plasma-optical emission spectrometry (ICP-OES) and graphite furnace atomic absorption spectrometry (GF-AAS) [35]. Concentration of trace elements beyond physiological limits in organs can be toxic in both animals and humans. Likewise, concentration of heavy metals such as $\mathrm{Pb}$ in the biological system are known to be toxic and affect biochemical reactions [35]. Further, bones remain a vital site for $\mathrm{Pb}$ accumulation after exposure, although circulating $\mathrm{Pb}$ in the blood can be distributed to various vital organs such as the brain, kidneys, and liver [62,63]. This present study decided to use ICP-MS for its superiority over other techniques and found significantly higher concentrations of $\mathrm{Pb}$ in the cerebellums of $\mathrm{Pb}$-induced rats when compared to their control counterparts. These results are in agreement with the previous works of Flora et al. [16], Sousa et al. [63], and Simsek et al. [35], who reported increased concentrations of $\mathrm{Pb}$ in the brains of $\mathrm{Pb}$-induced rats. A noteworthy finding was the administration of curcumin to $\mathrm{Pb}$-induced rats, which decreased the concentrations of $\mathrm{Pb}$ in their cerebellums. These findings were in accordance with the previous studies of Daniel et al. [64], Flora et al. [16], Mary et al. [24], and Shen et al. [65], who reported the chelating properties of curcumin. Daniel et al. [64] provided a 
background understanding of the chelating properties of curcumin on $\mathrm{Pb}$, resulting in a reduction of $\mathrm{Pb}$ concentration in the brain of rats by forming metal-ligand complexes through either directly bonding to the $\mathrm{Pb}$ molecules or via intermolecular hydrogen bonding. Further, the results obtained by Mary et al. [24] revealed that curcumin formed active chelates with zinc ions and suggested that curcumin as a multipotent agent could be best used in chelation therapies for numerous neurodegenerative diseases, such as Alzheimer's disease, and a radical scavenger where zinc ions are found in abundance. In addition, Shen et al. [65] documented the chelating properties of curcumin on copper (II) (Cu(II)) metal ions, which are implicated in the pathogenesis of Alzheimer's disease. Further, $\mathrm{Cu}$ (II) binds to at least two curcumin molecules [66]; the enolic proton in curcumin is readily dissociated in solution [67] as well as inspired by the 1:2 manganese (II) (Mn(II)) chelating mode of curcumin [68]. Interestingly, curcumin chelating potentials were also documented in other tissues, such as the liver, kidneys, and blood [16]. Flora et al. [16] assessed the protective effect of curcumin and nanocurcumin on $\mathrm{Pb}$-induced toxicity in the kidneys, livers, blood, and brains of mice. Further, the administration of curcumin and nanocurcumin revealed beneficial effects by attenuating the pathological lesion caused by toxic effect of $\mathrm{Pb}$, as well as reducing the concentration of $\mathrm{Pb}$ in the liver, brain, kidneys, and blood, although nanocurcumin showed more of a chelating effect than curcumin. Hence, the protective effect of curcumin was chiefly attributed to its scavenging of free radicals and chelating properties [15]. In addition, co-treatment with curcumin in female Kunming mice exposed to sodium arsenite in drinking water revealed amelioration of the adverse effect of arsenic toxicity on the liver and accelerated the excretion of arsenic via the urinary system [69,70]. Agarwal et al. [71] demonstrated in their work that pre-treatment and post-treatment with curcumin in rat models protected their livers and kidneys against mercury-induced toxicity, hence, curcumin chelated the mercury, resulting in a decreased concentration of mercury in the liver and kidneys.

In the present study, multiple pathological lesions were observed in the cerebellums of $\mathrm{Pb}$-induced rats. These changes included neuronal damage and alterations of the histological architecture of the cerebellar cortex. The Purkinje cells exhibited eosinophilic cytoplasm with darkly stained and irregular nuclei, leaving empty spaces between them. Semi-quantitative analysis of the Purkinje cells showed a significant increase $(p<0.05)$ in the number of necrotic Purkinje cells. Further, Pb-induced rats showed decreased $(p<0.05)$ cerebellar weights, which could be attributed to the marked degeneration of the cerebellar cells observed. These results are in accordance with several preceding studies $[9,37,48,72,73]$ that reported similar findings of neuronal degeneration in $\mathrm{Pb}$ and other heavy metal toxicity on the cerebellums, with more consequences for the Purkinje cells due to sensitivity of the Purkinje cell layer. Further, previous studies also documented the toxic effect of $\mathrm{Pb}$ administration on juvenile and young rats, resulting in different neurological impairments in various parts of the brain and nervous system [74-77]. However, treatment with curcumin reversed the above-mentioned $\mathrm{Pb}$-induced morphological aberrations in the rats. The results obtained from this study are in accordance with the results documented in previous studies on the attenuating effects of curcumin on $\mathrm{Pb}$-induced neurotoxicity [64,77-79]. These suggest that curcumin has antioxidant properties, as seen in the present study, or a combined antioxidant and anti-inflammatory role in neurotoxicity and neurodegenerative diseases, as documented by previous studies $[22,80,81]$.

The most important step in dealing with $\mathrm{Pb}$ toxicity is to avoid exposure to the sources of $\mathrm{Pb}$ contamination, which might not always be feasible. Therefore, standard drug chelators on the market exist, which are being used for heavy metal poisoning; however, they are expensive and exhibit many adverse effects $[17,18]$. This study revealed that withdrawal of $\mathrm{Pb}$ acetate alone was not enough to restore the damage inflicted by $\mathrm{Pb}$ toxicity on rats of the $\mathrm{RC}$ group. The persistent changes observed after $\mathrm{Pb}$ withdrawal include morphological aberrations of the cerebellum, decrease in motor scores on the horizontal bar test, oxidative stress, and high concentrations of $\mathrm{Pb}$ in the cerebellum as observed by ICP-MS analysis compared to the curcumin-treated groups. These could be due to specific kinetics, where a proportion of the absorbed $\mathrm{Pb}$ accumulates in the bone $[11,30,82]$ and is gradually released to soft tissues, such as the brain, kidneys, and liver $[30,82,83]$. Similar findings were reported by 
Omobowale [84], Nehru and Sidhu [49], and Khalaf et al. [85] after withdrawal of Pb exposure in rat models of $\mathrm{Pb}$ toxicity.

\section{Conclusions}

In consideration of the results obtained from this study, $\mathrm{Pb}$ toxicity resulted in decreased motor function, increased oxidative stress, aberrations in the histological structure of the cerebellum, and accumulation of $\mathrm{Pb}$ in the cerebellums of affected rats. Treatment with curcumin, regardless of the dose, attenuated the abnormalities caused by $\mathrm{Pb}$ toxicity, which could be due to the antioxidant and chelating properties of curcumin (Figure 18). To conclude, curcumin could be developed as a natural drug for treatment of $\mathrm{Pb}$ toxicity due to its therapeutic potential and wide pharmacological safety margin. Finally, the authors recommend future research on the activation of astrocytes and microglia involved in neurodegenerative diseases, as well as longer treatment periods with curcumin to assess the effectiveness of its long-term preclinical applications in $\mathrm{Pb}$-induced toxicity and neurodegeneration.

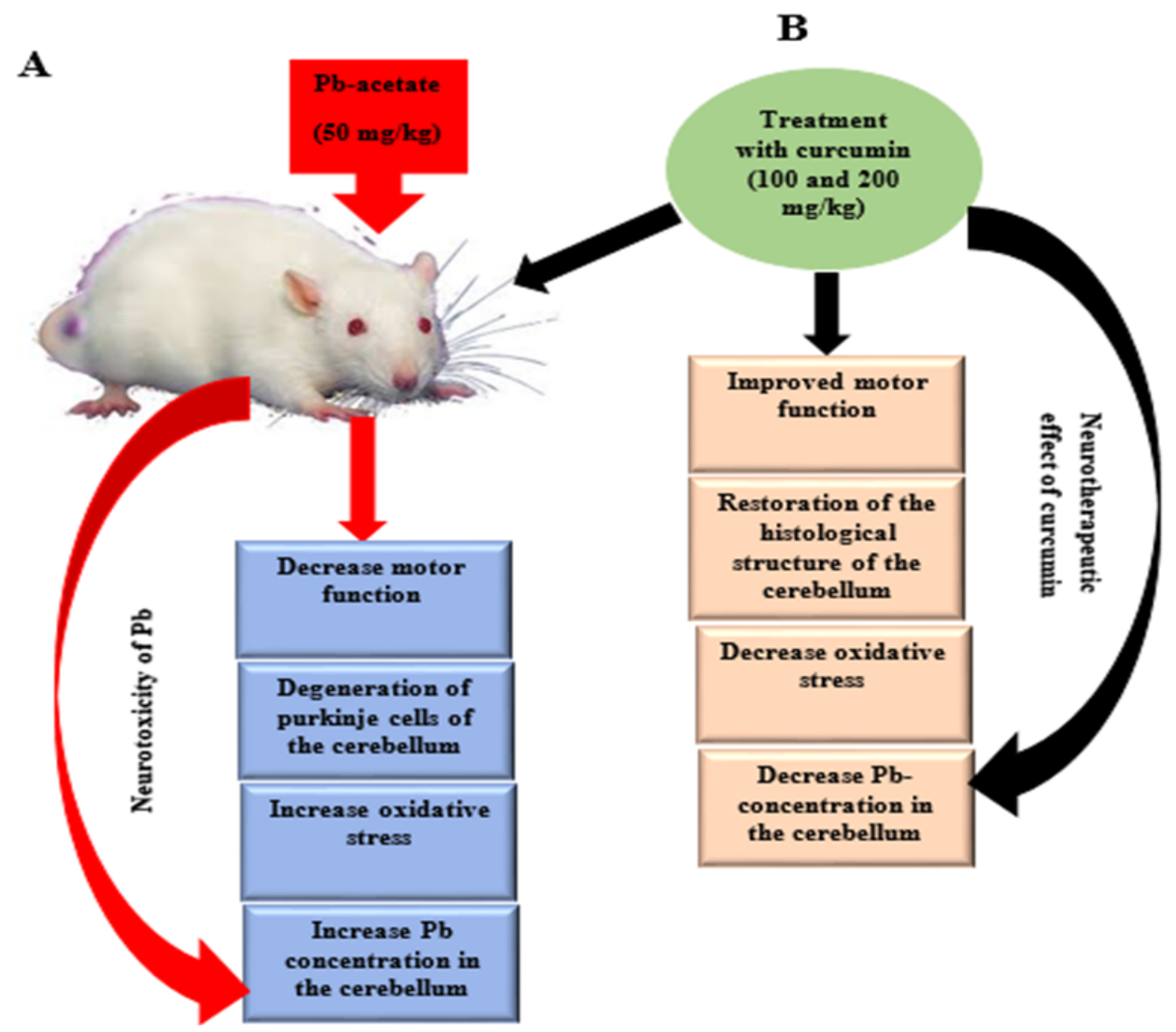

Figure 18. Proposed mechanism of Pb-induced cerebellar toxicity and the ameliorative effects of curcumin. $\mathrm{Pb}$ induction in rats, results in decreased motor function, degeneration of Purkinje cells of the cerebellum, increased oxidative stress, and increased $\mathrm{Pb}$ concentration in the cerebellum. Curcumin administration ameliorates the above-mentioned aberrations, which supports the neurotherapeutic effects of curcumin.

Author Contributions: Conceptualization, K.A., E.B.A.R., and M.Z.A.B.; methodology K.A., A.D., E.B.A.R., and M.Z.A.B.; validation, S.M.C., A.D., and M.Z.A.B.; formal analysis K.A., A.D., and M.M.M.; investigation, K.A., M.M.M., A.D., E.B.A.R., and M.Z.A.B.; data curation, K.A., M.M.M., S.M.C., and A.D.; writing-original draft preparation, K.A.; writing-review and editing, K.A., M.M.M., A.D., and S.M.C.; supervision, E.B.A.R. and M.Z.A.B.

Funding: This research was funded by Universiti Putra Malaysia, (Grant number GP-IPS 9663600). 
Acknowledgments: The authors would also like to acknowledge the support and effort of Saipulzaman Ali and Jamila Histopathology department, faculty of veterinary medicine, UPM.

Conflicts of Interest: The authors declare no conflict of interest.

\section{Abbreviations}

ABLES: Adult blood lead epidemiology and surveillance; BLLs: Blood lead levels; $\mathrm{Pb}$ : Lead; Pb acetate: Lead acetate; ROS: Reactive oxygen species; BBB: Blood-brain barrier; SAH: Subarachnoid hemorrhage; MDA: Malondialdehyde; MMP-9: Matrix metallopeptidase 9; $\mathrm{Mn}^{2+}$ : Manganese ion; $\mathrm{Fe}^{2+}$ : Iron ion; $\mathrm{Cu}^{2+}$ : Copper ion, $\mathrm{Zn}^{2+}$ : Zinc ion, HBM: Horizontal bar method; BCA: Bicinchronic acid assay; BSA: Bovine serum albumin; SOD: Superoxide dismutase; OD: Optical density; ICP-MS: Inductive-coupled plasma spectrometry; QC: Quality control; ANOVA: Analysis of variance; $\mathrm{H}$ and E: Hematoxylin and eosin; HD: Huntington disease.

\section{References}

1. El-Tantawy, W.H. Antioxidant effects of Spirulina supplement against lead acetate-induced hepatic injury in rats. J. Tradit. Complement. Med. 2016, 6, 327-331. [CrossRef] [PubMed]

2. Abdel-Zaher, A.O.; Abd-Ellatief, R.B.; Aboulhagag, N.A.; Farghaly, H.S.M.; Al-Wasei, F.M.M. The interrelationship between gasotransmitters and lead-induced renal toxicity in rats. Toxicol. Lett. 2019, 310, 39-50. [CrossRef] [PubMed]

3. Shaffer, R.M.; Gilbert, S.G. Reducing occupational lead exposures: Strengthened standards for a healthy workforce. Neurotoxicology 2017, 69, 181-186. [CrossRef] [PubMed]

4. Kosnett, M.J.; Wedeen, R.P.; Rothenberg, S.J.; Hipkins, K.L.; Materna, B.L.; Schwartz, B.S.; Hu, H.; Woolf, A. Recommendations for medical management of adult lead exposure. Environ. Health Perspect. 2007, 115, 463-471. [CrossRef]

5. Chowdhury, R.; Ebelt Sarnat, S.; Darrow, L.; McClellan, W.; Steenland, K. Mortality among participants in a lead surveillance program. Environ. Res. 2014, 132, 100-104. [CrossRef]

6. Flora, G.; Gupta, D.; Tiwari, A. Toxicity of lead: A review with recent updates. Interdiscip. Toxicol. 2012, 5, 47-58. [CrossRef]

7. Mason, L.H.; Harp, J.P.; Han, D.Y.; Mason, L.H.; Harp, J.P.; Han, D.Y. Pb neurotoxicity: Neuropsychological effects of lead toxicity. Biomed. Res. Int. 2014, 2014, 1-8. [CrossRef]

8. Chiodo, L.M.; Jacobson, S.W.; Jacobson, J.L. Neurodevelopmental effects of postnatal lead exposure at very low levels. Neurotoxicol. Teratol. 2004, 26, 359-371. [CrossRef]

9. Radad, K.; Hassanein, K.; Al-Shraim, M.; Moldzio, R.; Rausch, W.D. Thymoquinone ameliorates lead-induced brain damage in Sprague Dawley rats. Exp. Toxicol. Pathol. 2014, 66, 13-17. [CrossRef]

10. Andjelkovic, M.; Djordjevic, A.B.; Antonijevic, E.; Antonijevic, B.; Stanic, M.; Kotur-Stevuljevic, J.; Spasojevic-Kalimanovska, V.; Jovanovic, M.; Boricic, N.; Wallace, D.; et al. Toxic effect of acute cadmium and lead exposure in rat blood, liver, and kidney. Int. J. Environ. Res. Public Health 2019, 16, 274. [CrossRef]

11. Ishii, C.; Nakayama, S.M.M.; Kataba, A.; Ikenaka, Y.; Saito, K.; Watanabe, Y.; Makino, Y.; Matsukawa, T.; Kubota, A.; Yokoyama, K.; et al. Characterization and imaging of lead distribution in bones of lead-exposed birds by ICP-MS and LA-ICP-MS. Chemosphere 2018, 212, 994-1001. [CrossRef] [PubMed]

12. Ferreira, T.S.; Moreira, C.Z.; Cária, N.Z.; Victoriano, G.; Silva, W.F., Jr.; Magalhães, J.C. Phytotherapy: An introduction to its history, use and application. Rev. Bras. Plantas Med. 2014, 16, 290-298. [CrossRef]

13. Farid, R.M. A focus on curcumin local application in oral diseases management: Mini review. IOSR J. Pharm. 2016, 6, 30-40.

14. Mahmoudian-Sani, M.R.; Asadi-Samani, M.; Luther, T.; Saeedi-Boroujeni, A.; Gholamian, N. A new approach for treatment of type 1 diabetes: Phytotherapy and phytopharmacology of regulatory T cells. J. Ren. Inj. Prev. 2017, 6, 158-163. [CrossRef]

15. García-Niño, W.R.; Pedraza-Chaverrí, J. Protective effect of curcumin against heavy metals-induced liver damage. Food Chem. Toxicol. 2014, 69, 182-201. [CrossRef]

16. Flora, G.; Gupta, D.; Tiwari, A. Preventive efficacy of bulk and nanocurcumin against lead-induced oxidative stress in mice. Biol. Trace Elem. Res. 2013, 152, 31-40. [CrossRef]

17. Kabeer, A.; Mailafiya, M.M.; Danmaigoro, A.; Rahim, E.A.; Bakar, Z.A. Therapeutic potential of curcumin against lead-induced toxicity: A review. Biomed. Res. Ther. 2019, 6, 3053-3066. [CrossRef] 
18. Flora, S.J.S.; Pachauri, V. Chelation in metal intoxication. Int. J. Environ. Res. Public Health 2010, 7, $2745-2788$. [CrossRef]

19. Ghosh, S.S.; Gehr, T.W.B.; Ghosh, S. Curcumin and chronic kidney disease (CKD): Major mode of action through stimulating endogenous intestinal alkaline phosphatase. Molecules 2014, 19, 20139-20156. [CrossRef]

20. Hwang, E.S.; Lim, S.M.; Woo, E.J.; Kim, H.B.; Lee, S.; Choi, B.K.; Kwon, O.I.; Kim, H.J.; Kim, J.W.; Kyung, E.J. Evaluation of hepatoprotective effect of curcumin on liver cirrhosis using a combination of biochemical analysis and magnetic resonance-based electrical conductivity imaging. Mediat. Inflamm. 2018, 2018, 1-9. [CrossRef]

21. Hewlings, S.; Kalman, D. Curcumin: A review of its' effects on human health. Foods 2017, 6, 92. [CrossRef] [PubMed]

22. Shi, L.-Y.; Zhang, L.; Li, H.; Liu, T.-L.; Lai, J.-C.; Wu, Z.-B.; Qin, J. Protective effects of Curcumin on acrolein-induced neurotoxicity in HT22 mouse hippocampal cells. Pharmacol. Rep. 2018, 70, 1040-1046. [CrossRef] [PubMed]

23. Yuan, J.; Liu, W.; Zhu, H.; Zhang, X.; Feng, Y.; Chen, Y.; Feng, H.; Lin, J. Curcumin attenuates blood-brain barrier disruption after subarachnoid hemorrhage in mice. J. Surg. Res. 2017, 207, 85-91. [CrossRef] [PubMed]

24. Mary, C.P.V.; Vijayakumar, S.; Shankar, R. Metal chelating ability and antioxidant properties of Curcumin-metal complexes-A DFT approach. J. Mol. Graph. Model. 2017, 79, 1-14. [CrossRef] [PubMed]

25. Jo, O. Healing and prophylactic effects of moringa oleifera leaf extract on lead induced damage to haematological and bone marrow elements in adult wistar rat models. J. Aquac. Res. Dev. 2013, 1, 1-5. [CrossRef]

26. Ekanem, A.U.; Kwari, H.D.; Garba, S.H.; Salami, H.A. Effect of lead acetate on spleen and blood parameters in albino rats. IOSR J. Dent. Med. Sci. Ver. I 2015, 14, 43-49.

27. Zhang, Y.; Fang, M.; Sun, Y.; Zhang, T.; Shi, N.; Li, J.; Jin, L.; Liu, K.; Fu, J. Curcumin attenuates cerebral ischemia injury in Sprague-Dawley rats and PC12 cells by suppressing overactivated autophagy. J. Photochem. Photobiol. B Biol. 2018, 184, 1-6. [CrossRef] [PubMed]

28. Kim, J.; Lee, Y.; Yang, M. Environmental exposure to lead $(\mathrm{Pb})$ and variations in its susceptibility. J. Environ. Sci. Heal. Part. C Environ. Carcinog. Ecotoxicol. Rev. 2014, 32, 159-185. [CrossRef]

29. Brown, M.J.; Margolis, S. Lead in drinking water and human blood lead levels in the United States. MMWR Surveill. Summ. 2012, 61,1-9.

30. Mushak, P. Lead Exposure in Human Populations: Lead Toxicokinetics and Biomarkers of Lead Exposure; Elsevier: Amsterdam, The Netherlands, 2011; Volume 10, pp. 243-316. ISBN 9780444515544.

31. Sarada, S.K.S.; Titto, M.; Himadri, P.; Saumya, S.; Vijayalakshmi, V. Curcumin prophylaxis mitigates the incidence of hypobaric hypoxia-induced altered ion channels expression and impaired tight junction proteins integrity in rat brain. J. Neuroinflamm. 2015, 12, 1-18. [CrossRef]

32. Ma, J.; Liu, J.; Yu, H.; Wang, Q.; Chen, Y.; Xiang, L. Curcumin promotes nerve regeneration and functional recovery in rat model of nerve crush injury. Neurosci. Lett. 2013, 547, 26-31. [CrossRef] [PubMed]

33. Deacon, R.M.J. Measuring motor coordination in mice. J. Vis. Exp. 2013, 75, 1-8. [CrossRef] [PubMed]

34. Rattanachongkiat, S.; Millward, G.E.; Foulkes, M.E. Determination of arsenic species in fish, crustacean and sediment samples from Thailand using high performance liquid chromatography (HPLC) coupled with inductively coupled plasma mass spectrometry (ICP-MS). J. Environ. Monit. 2004, 6, 254-261. [CrossRef] [PubMed]

35. Simsek, N.; Akinci, L.; Alan, H.; Gecör, O.; Özan, Ü. Determination of trace elements in kidneys, livers and brains of rats with sealer implants by ICP-MS. Biotechnol. Biotechnol. Equip. 2017, 31, 397-402. [CrossRef]

36. Costa, P.M. The handbook of histopathological practices in aquatic environment: Guide to histology for environmental toxiccology; Academic Press: London, UK, 2018; p. 292. ISBN 9780128120323.

37. Mohammed Raouf, G.A.; Vaibhav, K.; Khan, A.; Tabassum, R.; Ahmed, M.E.; Javed, H.; Chander, K.; Islam, F.; Siddiqui, M.S. Terminalia arjuna bark extract inhibits histological alterations by mitigating oxidative stress in lead intoxicated mice. Orient. Pharm. Exp. Med. 2013, 13, 253-265. [CrossRef]

38. Aldahmash, B.A.; El-Nagar, D.M. Antioxidant effects of captopril against lead acetate-induced hepatic and splenic tissue toxicity in Swiss albino mice. Saudi J. Biol. Sci. 2016, 23, 667-673. [CrossRef]

39. Sanders, T.; Liu, Y.; Buchner, V.; Tchounwou, P.B. Neurotoxic effects and biomarkers of lead exposure: A review. Rev. Environ. Health 2009, 24, 15-45. [CrossRef] 
40. Brochin, R.; Leone, S.; Phillips, D.; Shepard, N.; Zisa, D.; Angerio, A. The cellular effect of lead poisoning and its clinical picture. Georg. Undergrad. J. Health Sci. 2008, 5, 1-8.

41. Garza, A.; Vega, R.; Soto, E. Cellular mechanisms of lead neurotoxicity. Med. Sci Monit. 2006, 12, RA57-RA65.

42. Offor, S.J.; Mbagwu, H.O.C.; Orisakwe, O.E. Lead induced hepato-renal damage in male albino rats and effects of activated charcoal. Front. Pharmacol. 2017, 8, 1-10. [CrossRef]

43. Chiroma, S.; Baharuldin, M.; Mat Taib, C.; Amom, Z.; Jagadeesan, S.; Ilham Adenan, M.; Mahdi, O.; Moklas, M. Protective effects of centella asiatica on cognitive deficits induced by D-gal/AlCl3 via inhibition of oxidative stress and attenuation of acetylcholinesterase level. Toxics 2019, 7, 19. [CrossRef] [PubMed]

44. Llaneza, D. Progestogens and estrogen influence impulsive burying and avoidant freezing behavior of OVX rats. J. Pharmacol. Exp. Ther. 2009, 93, 337-342.

45. Frye, C.A.; Llaneza, D.C.; Walf, A.A. Progesterone can enhance consolidation and/or performance in spatial, object and working memory tasks in Long-Evans rats. Anim. Behav. 2009, 78, 279-286. [CrossRef] [PubMed]

46. Adolph, K.E.; Franchak, J.M. The development of motor behavior. Wiley Interdiscip. Rev. Cogn. Sci. 2017, 8, 1-30. [CrossRef] [PubMed]

47. Manto, M. Toxic Agents Causing Cerebellar Ataxias; Elsevier: Amsterdam, The Netherlands, 2012.

48. El-Eraky El-Azab, N.; El-Mahalaway, A.M.; Sabry, D. Effect of methyl mercury on the cerebellar cortex of rats and the possible neuroprotective role of mesenchymal stem cells conditioned medium. histological and immunohistochemical study. J. Stem Cell. Res. Ther. 2018, 8, 2. [CrossRef]

49. Nehru, B.; Sidhu, P. Neurotoxic effects of differential doses of lead on rat brain followed by recovery. J. Trace Elem. Exp. Med. 2002, 15, 131-140. [CrossRef]

50. Barkur, R.R.; Bairy, L.K. Histological study on hippocampus, amygdala and cerebellum following low lead exposure during prenatal and postnatal brain development in rats. Toxicol. Ind. Health 2014, 32, 1052-1063. [CrossRef]

51. Sabbar, M.; Delaville, C.; De Deurwaerdère, P.; Lakhdar-Ghazal, N.; Benazzouz, A. Lead-induced atypical Parkinsonism in rats: Behavioral, electrophysiological, and neurochemical evidence for a role of noradrenaline depletion. Front. Neurosci. 2018, 12, 1-13. [CrossRef]

52. Moore, T.L.; Bowley, B.G.E.; Shultz, P.L.; Calderazzo, S.M.; Shobin, E.J.; Uprety, A.R.; Rosene, D.L.; Moss, M.B. Oral curcumin supplementation improves fine motor function in the middle-aged rhesus monkey. Somatosens. Mot. Res. 2018, 35, 1-10. [CrossRef]

53. Chongtham, A.; Agrawal, N. Curcumin modulates cell death and is protective in Huntington's disease model. Sci. Rep. 2016, 6, 1-10. [CrossRef]

54. Santos-Parker, J.R.; Lubieniecki, K.L.; Rossman, M.J.; Van Ark, H.J.; Bassett, C.J.; Strahler, T.R.; Chonchol, M.B.; Justice, J.N.; Seals, D.R. Curcumin supplementation and motor-cognitive function in healthy middle-aged and older adults. Nutr. Heal. Aging 2018, 4, 323-333. [CrossRef] [PubMed]

55. Breitenbach, M. Oxidative stress and neurodegeneration: The yeast model system. Front. Biosci. 2013, 18, 1174. [CrossRef]

56. Patrick, L. Lead Toxicity, a review of the literature part l' exposure, evaluation, and treatment. Altern. Med. Rev. 2006, 11, 2-22. [PubMed]

57. Swomley, A.M.; Butterfield, D.A. Oxidative stress in Alzheimer disease and mild cognitive impairment: Evidence from human data provided by redox proteomics. Arch. Toxicol. 2015, 89, 1669-1680. [CrossRef] [PubMed]

58. Ali, B.H.; Al-Salam, S.; Al Suleimani, Y.; Al Kalbani, J.; Al Bahlani, S.; Ashique, M.; Manoj, P.; Al Dhahli, B.; $\mathrm{Al}$ Abri, N.; Naser, H.T.; et al. Curcumin ameliorates kidney function and oxidative stress in experimental chronic kidney disease. Basic Clin. Pharmacol. Toxicol. 2018, 122, 65-73. [CrossRef] [PubMed]

59. Alisi, I.O.; Uzairu, A.; Abechi, S.E.; Idris, S.O. Evaluation of the antioxidant properties of curcumin derivatives by genetic function algorithm. J. Adv. Res. 2018, 12, 47-54. [CrossRef] [PubMed]

60. Priyadarsini, K.I.; Maity, D.K.; Naik, G.H.; Kumar, M.S.; Unnikrishnan, M.K.; Satav, J.G.; Mohan, H. Role of phenolic $\mathrm{O}-\mathrm{H}$ and methylene hydrogen on the free radical reactions and antioxidant activity of curcumin. Free Radic. Biol. Med. 2003, 35, 475-484. [CrossRef]

61. Ammerman, J.; Huang, C.; Sailstad, J.; Wieling, J.; Whitmire, M.L.; Wright, D.; De Lisio, P.; Keenan, F.; McCurdy, E.; Woods, B.; et al. Technical aspects of inductively coupled plasma bioanalysis techniques. Bioanalysis 2013, 5, 1831-1841. [CrossRef] 
62. Renner, R. Exposure on tap: Drinking water as an overlooked source of lead. Environ. Health Perspect. 2010, 118, A68-A74. [CrossRef]

63. De Sousa, R.A.; Sabarense, C.M.; Prado, G.L.P.; Metze, K.; Cadore, S. Lead biomonitoring in different organs of lead intoxicated rats employing GF AAS and different sample preparations. Talanta 2013, 104, 90-96. [CrossRef]

64. Daniel, S.; Limson, J.L.; Dairam, A.; Watkins, G.M.; Daya, S. Through metal binding, curcumin protects against lead- and cadmium-induced lipid peroxidation in rat brain homogenates and against lead-induced tissue damage in rat brain. J. Inorg. Biochem. 2004, 98, 266-275. [CrossRef] [PubMed]

65. Shen, L.; Zhang, H.Y.; Ji, H.F. A theoretical study on $\mathrm{Cu}$ (II)-chelating properties of curcumin and its implications for curcumin as a multipotent agent to combat Alzheimer's disease. J. Mol. Struct. THEOCHEM 2005, 757, 199-202. [CrossRef]

66. Baum, L.; $\mathrm{Ng}, \mathrm{A}$. Curcumin interaction with copper and iron suggests one possible mechanism of action in Alzheimer's disease animal models. J. Alzheimer Dis. 2004, 6, 367-377. [CrossRef]

67. Borsari, M.; Ferrari, E.; Grandi, R.; Saladini, M. Curcuminoids as potential new iron-chelating agents: Spectroscopic, polarographic and potentiometric study on their Fe (III) complexing ability. Inorg. Chim. Acta 2002, 328, 61-68. [CrossRef]

68. Sumanont, Y.; Murakami, Y.; Tohda, M.; Vajragupta, O.; Matsumoto, K.; Watanabe, H. Evaluation of the nitric oxide radical scavenging activity of manganese complexes of curcumin and its derivative. Biol. Pharm. Bull. 2004, 27, 170-173. [CrossRef] [PubMed]

69. Hou, G.; Surhio, M.M.; Ye, H.; Gao, X.; Ye, Z.; Li, J.; Ye, M. Protective effects of a Lachnum polysaccharide against liver and kidney injury induced by lead exposure in mice. Int. J. Biol. Macromol. 2019, 124, 716-723. [CrossRef] [PubMed]

70. Yadav, A.; Lomash, V.; Samim, M.; Flora, S.J.S. Curcumin encapsulated in chitosan nanoparticles: A novel strategy for the treatment of arsenic toxicity. Chem. Biol. Interact. 2012, 199, 49-61. [CrossRef] [PubMed]

71. Agarwal, R.; Goel, S.K.; Behari, J.R. Detoxification and antioxidant effects of curcumin in rats experimentally exposed to mercury. J. Appl. Toxicol. 2010, 30, 457-468. [CrossRef] [PubMed]

72. Sidhu, P.; Nehru, B. Lead intoxication: Histological and oxidative damage in rat cerebrum and cerebellum. J. Trace Elem. Exp. Med. 2004, 17, 45-53. [CrossRef]

73. Nam, S.M.; Seo, J.S.; Nahm, S.S.; Chang, B.J. Effects of ascorbic acid on osteopontin expression and axonal myelination in the developing cerebellum of lead-exposed rat pups. Int. J. Environ. Res. Public Health 2019, 16, 983. [CrossRef] [PubMed]

74. NourEddine, D.; Miloud, S.; Abdelkader, A. Effect of lead exposure on dopaminergic transmission in the rat brain. Toxicology 2005, 207, 363-368. [CrossRef] [PubMed]

75. Adekomi, D.A.; Adewole, O.S.; Tijani, A.A.; Adeniyi, T.D. Lead induces inflammation and neurodegenerative changes in the rat medial prefrontal cortex. Anatomy 2018, 11, 79-86. [CrossRef]

76. Goulart, E.C.; Pereira, C.A.T.; Garcia, R.C.; Giacomelli, M.B.O.; Rodrigues, A.L.S. Effects of lead and/or zinc exposure during the second stage of rapid postnatal brain growth on delta-aminolevulinate dehydratase and negative geotaxis of suckling rats. Braz. J. Med. Biol. Res. 2001, 34, 785-790. [CrossRef] [PubMed]

77. Shukla, P.K.; Khanna, V.K.; Khan, M.Y.; Srimal, R.C. Protective effect of curcumin against lead neurotoxicity in rat. Hum. Exp. Toxicol. 2003, 22, 653-658. [CrossRef] [PubMed]

78. Tüzmen, M.N.; Yücel, N.C.; Kalburcu, T.; Demiryas, N. Effects of curcumin and tannic acid on the aluminum-and lead-induced oxidative neurotoxicity and alterations in NMDA receptors. Toxicol. Mech. Methods 2015, 25, 120-127. [CrossRef] [PubMed]

79. Dairam, A.; Limson, J.L.; Watkins, G.M.; Antunes, E.; Daya, S. Curcuminoids, curcumin, and demethoxycurcumin reduce lead-induced memory deficits in male wistar rats. J. Agric. Food Chem. 2007, 55, 1039-1044. [CrossRef]

80. Wang, R.; Li, Y.H.; Xu, Y.; Li, Y.B.; Wu, H.L.; Guo, H.; Zhang, J.Z.; Zhang, J.J.; Pan, X.Y.; Li, X.J. Curcumin produces neuroprotective effects via activating brain-derived neurotrophic factor/TrkB-dependent MAPK and PI-3K cascades in rodent cortical neurons. Prog. Neuro Psychopharm. Biol. Psychiatr. 2010, 34, 147-153. [CrossRef]

81. Samarghandian, S.; Azimi-nezhad, M.; Farkhondeh, T. Anti-oxidative effects of curcumin on immobilization-induced oxidative stress in rat brain, liver and kidney. Biomed. Pharmacother. 2017, 87, 223-229. [CrossRef] 
82. Wani, A.L.; Ara, A.; Usmani, J.A. Lead toxicity: A review. Interdiscip. Toxicol. 2015, 8, 55-64. [CrossRef]

83. Barbosa, F.; Tanus-Santos, J.E.; Gerlach, R.F.; Parsons, P.J. A critical review of biomarkers used for monitoring human exposure to lead: Advantages, limitations, and future needs. Environ. Health Perspect. 2005, 113, 1669-1674. [CrossRef]

84. Omobowale, T.O.; Oyagbemi, A.A.; Akinrinde, A.S.; Saba, A.B.; Daramola, O.T.; Ogunpolu, B.S.; Olopade, J.O. Failure of recovery from lead induced hepatoxicity and disruption of erythrocyte antioxidant defence system in Wistar rats. Environ. Toxicol. Pharmacol. 2014, 37, 1202-1211. [CrossRef] [PubMed]

85. Khalaf, A.A.; Moselhy, W.A.; Abdel-Hamed, M.I. The protective effect of green tea extract on lead induced oxidative and DNA damage on rat brain. Neurotoxicology 2012, 33, 280-289. [CrossRef] [PubMed]

(C) 2019 by the authors. Licensee MDPI, Basel, Switzerland. This article is an open access article distributed under the terms and conditions of the Creative Commons Attribution (CC BY) license (http://creativecommons.org/licenses/by/4.0/). 